\title{
The Impacts of Different Climate Change Scenarios on Visits toward the National Forest Park in Taiwan
}

\author{
Wan-Yu Liu ${ }^{1}{ }^{1}$, Yen-Hsiang Huang ${ }^{1}$ and Chi-Ming Hsieh ${ }^{2, *}$ \\ 1 Innovation and Development Center of Sustainable Agriculture, Department of Forestry, \\ National Chung Hsing University, 145 Xingda Rd., South Dist., Taichung City 40227, Taiwan; \\ wyliu@nchu.edu.tw (W.-Y.L.); chowder@smail.nchu.edu.tw (Y.-H.H.) \\ 2 International Bachelor Program of Agribusiness, National Chung Hsing University, \\ Taichung City 40227, Taiwan \\ * Correspondence: hsiehch9@nchu.edu.tw
}

Received: 13 October 2020; Accepted: 12 November 2020; Published: 15 November 2020

\begin{abstract}
Many studies have shown that the weather greatly affects the tourist count. Understanding weather information, climate change, and how they influence the tourist count in different tourist seasons (peak season, second peak season, off season) can help park planners and managers to analyze the opportunities and risks caused by climate change. This study aimed to predict the visitor count through information on the number of visitors and the weather day for three tourist seasons in a 12-month period. The study was conducted in the Huisun Forest Park of Taiwan based on the peak season (February, July, August, and October), the second peak season (January, April, May, November, and December), and the off-season (March, June, and September), using weather factors and virtual factors (such as whether it is a weekend or not) to establish three multivariate regression models for predicting the daily visitor count. This study assessed the impact of climate change on the visitor count and analyzed possible scenarios of climate change using representative concentration pathways (RCPs), as stated in the fifth assessment report of the Intergovernmental Panel on Climate Change (IPCC). The results of this study indicated that the impacts of weather factors on the visitor count is the same for the peak season and the off season. The temperature and relative humidity have a significant impact on the visitor count, and precipitation is not significant. In the second peak season, only the temperature has a significant impact on the visitor count. The relative humidity and precipitation are not significant. The temperature is the most influential factor in all three seasons, and has the highest influence on the peak season, followed by the low season, and then the second peak season. In addition, the number of visitors in Huisun Forest Park is on the rise, according to an analysis of various climate change scenarios (RCP2.6, RCP4.5, RCP6.0, RCP8.5). The results of this study can be used as a reference by forest park managers and future researchers. It is noted that the results were based on the current economic and political situation. The worsening of the entire world situation could break the relationships.
\end{abstract}

Keywords: weather factors; visitation; climate change

\section{Introduction}

According to previous literature, the weather greatly affects the number of tourists [1-10]. According to the Intergovernmental Panel on Climate Change (IPCC) (2014a) [11], the definition of climate is the average weather over a period of time (usually 30 years), usually by the earth surface's measurable variability, such as temperature, precipitation, and wind measurement. The definition of weather is the atmospheric condition at a specific time and place [12]. The United Nations Framework Convention on Climate Change (UNFCCC) defines climate change as the change of climate that changes 
the composition of the global atmosphere due to human direct or indirect activities outside of natural climate change [11]. If climate factors and possible climate change can be further understood regarding how they will affect the tourist peak/off season and tourist count, park planners and managers can better understand the opportunities and risks under the human-induced global climate change, and this information can help develop more comprehensive management decisions and development policies for facilities and conservation. One way to understand the impact of the weather is through a more detailed (such as time sequence) tourist count. Getting the most modern and accurate information related to climate change information that may affect the tourist count will be important for forest park managers and government policy makers in developing comprehensive climate change strategies. If the information received by managers and government receive is complete, their decisions will likely minimize the risk of future climate change and maximize potential opportunities [13].

Through the past literature [2,13], the impact on the number of tourists from weather sensitivity and threshold temperature can be understood. Smit, Burton, Klein, and Wandel (2000) [14] pointed out that weather sensitivity refers to the degree the system is affected or reacted by weather changes; Jones and Scott $(2006 a, b)$ [5,6] speculate that threshold temperature-when temperature exceeds a critical point that becomes too hot and causes the critical point temperature to drop the tourist count. Jones and Scott (2006a, 2006b) [5,6] studied the impact of climate change on the tourist count in Canada, using provincial- and national-level data to verify. With the study in Australia, Hadwen et al. (2011) [3] pointed out that natural factors and institutional factors will affect the tourist count in the tourist peak/off season. According to the study of Butler (2001) [15], the tourist peak/off season caused by natural factors is related to the natural cycle, especially the changes in the weather (such as temperature and precipitation); the tourist peak/off seasons caused by institutional factors are human activities and policies (such as schools and national holidays), including traditional and national holidays or festivals, two days off every week, and other variables. Scott, Jones, and Konopek (2008) [16], in the study of tourists' preferences, found that the statistical relationships between tourism demand (such as tourist count) and weather/climate (the weather or climate decided by the available data) can be used to infer tourists' preferences.

The study results of Hewer et al. (2015) [4] pointed out that if there is sun or not and comfortable temperature are the two most important climate factors in a summer months camper satisfaction survey of the two provincial forest parks in the Canadian city of Ontario. Weather factors, such as heavy rains and strong winds, have the greatest impact on campers' willingness to stay and the decision to leave the park early. Not only that, Hewer et al. (2015) [4] concluded that during the summer season, daytime temperatures below 16 degrees are considered to be too cold, between 24 and 31 degrees is considered ideal, and that above 35 degrees is considered too hot; also, in the summer season, night time temperatures below 9 degrees are considered too cold, between 17 and 24 degrees is considered ideal, and that above 29 degrees is considered too hot. However, when different methods are used, it is still pending further discussion whether or not the importance of different climate factors obtained in the same park are the same.

According to studies by Buckley and Foushee (2011) [1], Fisichelli et al. (2015) [2], Jones and Scott (2006a) [5], and Hewer et al. (2016) [13], climate change also has an impact on the number of tourists. Buckley and Foushee (2011) [1] analyzed the average monthly temperature and tourist count in the US national parks from 1979 to 2008, and learned that the date of the peak temperature in 2008 appeared four days earlier on average than that in 1979. Monahan and Fisichelli (2014) [17] determined that most national parks have reached the highest temperature range of historical changes by observing the climatic data of 289 US national parks during the period 1901-2012. Fisichelli et al. (2015) [2] established a regression model to predict the potential impact of climate change on national parks based on the average monthly climate and tourist count in 340 national parks from 1979 to 2013. Overall, the study concluded that global warming caused by climate change will prolong the travel season period and increase the number of tourists. Jones and Scott (2006a) [5] pointed out that the number of tourists in national parks will increase by $11 \%-27 \%$ in the 2020 s, $15 \%-56 \%$ in the 2050 s, 
and $19 \%-82 \%$ in the 2080 s. The tourist count is expected to increase mainly in the second peak season (spring and autumn), but the tourist count in the peak season (summer) is also expected to increase. The regression model shows that the tourist count will increase as the possible climate change will lead to a longer warmer tourist season. Although there have been many articles on national park research in the United States recently, there are still no studies using daily data to further understand the relationship between weather and tourist count.

Jones and Scott (2006a) [5] established multivariate regression analysis with monthly climate and tourist count data between 1989 and 2003 to predict the potential impact of climate change on six provincial forest parks in Ontario. In order to explain the seasonal impact of natural and institutional factors in the historical tourist record, the study established regression equations for the peak season and the second peak season, respectively. Loomis and Richardson (2006) [7] used monthly climate and tourist count data from 1987 to 1999 to establish a multivariate regression model in which the variables used included social variables to control population growth and weekend holidays, and finally to conclude the number of tourists that may increase under the potential climate change. Hadwen et al. (2011) [3] used monthly data to build a multivariate regression model across Australia of different climate zones to compare the effects of climatic factors (temperature, precipitation) and social variables (schools, national holidays) on the number of tourists. The results concluded that the weather factor is the main determinant of the number of tourists in the conservation area, especially in climate zones with high climate variability (such as temperate zone); in zones with relatively stable environments (such as a sub-tropical zone), the determinants are social factors. However, when the regression model is performed using daily data, the results will remain the same or change and will need to be determined again.

Hewer et al. (2016) [13] used multiple linear regressions to establish a model of weather and tourist count for three seasons (peak season, second peak season, and off season). In order to explain the impact of natural factors and institutional factors on the number of tourists, these three models included weather factors, such as temperature, precipitation, etc., and also included social factors, such as weekends, national holidays, etc. Under these three models, the degree of impact of these factors is comparable. After using one-way ANOVA to find the threshold temperature of the three seasons, it was discovered that a temperature above $33^{\circ} \mathrm{C}$ during the peak season and above $29^{\circ} \mathrm{C}$ during the second peak season is too hot for tourists, resulting in a decrease in the number of tourists, while $11^{\circ} \mathrm{C}$ during the off season is another threshold temperature, with most tourists feeling it is too cold under this condition; therefore, lower than this temperature, temperature changes are less sensitive to the number of tourists. In order to understand the impact of a warm and humid climate on the tourist count, the impact of the maximum temperature rise of $1{ }^{\circ} \mathrm{C}$ to $5{ }^{\circ} \mathrm{C}$ on that day was examined, and the total precipitation on the day increased by $5 \%$ to $15 \%$ on the tourist count after performing a partial sensitivity analysis on the tourist count. Under the possible climate change scenario, the model of weather and tourist count shows that when the daily maximum temperature rises by $1{ }^{\circ} \mathrm{C}$, although the possibilities of total precipitation and extreme weather increase, the tourist count still grows at a rate of $3.1 \%$ per year. Along with the increase of temperature, the main reason for the increase in the tourist count is related to the increase in the number of tourists in the second peak season, while the number of tourists in the peak season only increased slightly.

Using the forest park as a recreation area is nature-based ecotourism, defined as a recreational activity or a tourist experience that is determined or increased by the natural environment [18,19]. Hewer et al. (2016) [13] pointed out that Ontario's public recreation area relies on its own funds and income to maintain the operations; therefore, any change in the number of tourists will seriously affect the park management and park conservation ability. The financial income of the park is mainly dependent on tourists and tourist spending will also increase employment opportunities and economic income for residents in the vicinity.

Summarizing the above discussion, we can understand that the international studies have attached great importance to the impact of weather factors and climate change on the number of tourists; 
however, there are only a few international studies on this topic, and few studies use daily data to understand the relationship between weather, tourism peak and the off seasons, and the threshold temperature of peak and off seasons with the number of tourists, thus comprehensively examining the impact of natural and institutional factors on the number of tourists [13]. Therefore, this study used the Huisun Forest Park in Nantou County, Taiwan as the survey area, and used the weather factors and the future possible climate change scenarios provided by the Ministry of Science and Technology (2018) [20] to explore its impact on the number of tourists.

This study mainly answers the following questions: (1) Is the weather sensitivity of the number of downstream tourists in different seasons the same? (2) What climatic factors have the most impact on the number of tourists? (3) Are the climatic factors of different seasons the same? (4) Is there a temperature turning point in the correlation between temperature and number of tourists? In other words, does a maximum number of tourists for a certain temperature point exist? Are the temperature turning points for different tourism seasons different? (5) What is the predicted impact of simulating the possible future climate change scenarios on the number of tourists?

\section{Materials and Methods}

\subsection{Study Area}

This study was conducted in the Huisun Forest Park in Renai Township, Nantou County, Taiwan. It is one of Taiwan's national forest parks and also one of the experimental forest parks affiliated to the Experimental Forest Management Office, National Chung Hsing University. It has a long history and existed during the Japanese colonial period. It has $85 \%$ of the original forests, and it has three different climatic characteristics: sub-tropical, warm temperate, and temperate zone because of the large altitude difference, thus, it has rich forests, a wide variety of flora and fauna, and preserves some precious species. Further, as it is under the impact of being upstream to the Beigang River and Guandau River incision force, it forms a special natural landscape and is an appropriate place for teaching and research, not only appreciating the natural scenery here, but also enjoying leisure activities, such as forest bathing, picnics, walking, and water play [21,22]. Therefore, it has attracted many tourists every year. According to the statistics of the Tourism Bureau, Ministry of Transportation and Communications [23], the number of tourists visiting Huisun Forest Park in the past 10 years has increased every year. The average number of tourists in the past 10 years was 174,270 persons per year, and the number reached 204,387 in 2015 (Figure 1).

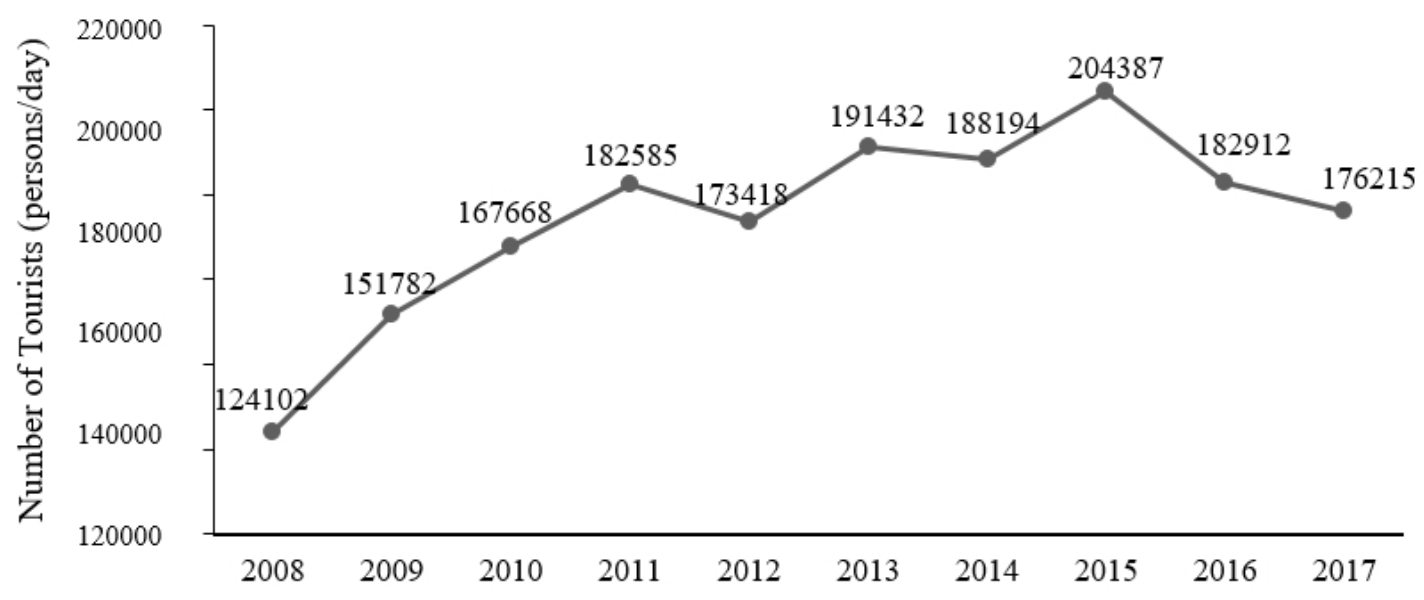

Figure 1. The number of tourists per year for Huisun Forest Park in the past 10 years.

\subsection{Number of Tourists (Persons per Day)}

First, the forecast model of this study includes different climate change scenarios considering the number of tourists. 


\subsubsection{Global Climate Model (GCM)}

The Taiwan Climate Change Projection Information and Adaptation Knowledge Platform (TCCIP), Ministry of Science and Technology is based on the Fifth Assessment Report of the Intergovernmental Panel on Climate Change [24], which selected 41 monthly average rainfall data (unit: millimeters per day; $\mathrm{mm} / \mathrm{d}$ ) and the monthly average surface temperature data $\left({ }^{\circ} \mathrm{C}\right)$ of 41 AGCM models for analysis. Fenech, Comer, and Gough (2007) [25] pointed out that many methods are developed to provide a basis for judging which IPCC Fifth Assessment Reports is the most suitable to provide the future climate change prediction. The ensemble approach is based on recent scientific literature [13] showing that the ensemble approach is most suitable to provide future climate change predictions. This approach can reduce the uncertainty of any single model by averaging the predictions of all or most of the climate models to obtain average climate change, and may offset the deviation of each model by taking all models into consideration. Compared with historical climate data observed in the past, the climate predictions obtained by the ensemble approach are the closest to historical data.

\subsubsection{Statistical Downscaling}

According to Liu (2015) [26] pointed out that downscaling is an approach to improve spatial resolution. There are two approaches for downscaling the results of the global climate model. One is statistical downscaling and the other is dynamical downscaling. Statistical downscaling uses long-term observation data as the baseline (i.e., estimation factors) to establish long-term and stable statistical relationships with the past simulation data of the climate model (i.e., estimation variables), and to apply the statistical relationship between the estimation factors and estimation variables to the estimation data of climate models in the near future and the end of the century. When the density of the observation data network is higher, it can provide a more detailed spatial distribution to correct the lower resolution model data (resolution of about $250 \mathrm{~km}$ ), and then use the statistical approach to correct the error between different sets of global climate model data, as well as the errors that may be caused by downscaling, and further calculated the climate estimation data of Taiwan area. The reason why it is called statistical downscaling is because the approach is used to seek a stable statistical relationship between the observation and model, where the more stable the relationship between the two, the more reliable the downscaling effect obtained. On the other hand, the higher the spatial density of the observed data, the more details can be provided to the model data, so the resolution of the observed data (TCCIP currently provides $5 \mathrm{~km}$ of gridded observed data) directly determines the resolution of the downscaling when using statistical approaches to downscale [20].

\subsubsection{Simulation Scenario of Climate Change in Taiwan}

In the Fifth Assessment Report of IPCC [24], the "Representative Concentration Pathways (RPCs)" (the pathways refer to the change course of concentration) is used to redefine the four groups of future changes, and to use the variation of radiative forcing between 2100 and 1750 as the indicator value to distinguish. The scenario named RCP2.6 means that the radiative forcing per square meter increased by 2.6 watts in 2100 , while RCP4.5, RCP6.0, and RCP 8.5 represent an increase in radiative forcing by $4.5,6.0$, and 8.5 watts per square meter. In these four scenarios, RCP2.6 is a warming-slowing scenario (radiative forcing shows a decreasing trend in 2100), RCP4.5 and RCP6.0 are stable scenarios (changes in radiative forcing show a stable state in 2100), and RCP8.5 is a scenario in which greenhouse gases are highly emitted (radiative forcing shows a continuing increasing trend in 2100) [20].

Pielke and Wilby (2012) [27] pointed out that under global or regional climate models, including statistical downscaling and dynamic downscaling, with known uncertainties, the results obtained by climate models have become increasingly difficult to use in guiding the establishment of countermeasures. However, Whetton, Hennessy, Clarke, McInnes, and Kent (2012) [28] showed that downscaled climate change does not need to be bound by a specific climate model; instead, a representative climate can be used, or a brief description of future weather, such as "hotter", "drier", 
or "more unstable", to describe them. In order to establish contemporary climatic conditions and predict climate change, it is necessary to have daily temperature and precipitation data as well as the nearest weather station to be selected to correct the statistical downscaling model to produce comprehensive weather data.

In order to further explore the impact on the number of tourists in different climate change scenarios in the future, this study used the future evaluation professional version of the TCCIP website to select the Experimental Forest Road of National Chung Hsing University, Renai Township, Nantou County, Taiwan (longitude $121.04^{\circ} \mathrm{E}$, latitude $24.07^{\circ} \mathrm{N}$ ), selecting temperature as the parameter, ensemble as the model, and year as the time to obtain the estimated average temperature $\left({ }^{\circ} \mathrm{C}\right)$ per year for 2020-2100; precipitation was selected as the parameter, ensemble as the model, and year as the time to obtain the estimated average daily total precipitation ( $\mathrm{mm}$ per day) per year. To obtain the predicted value of future climate change, as shown in Figure 2, RCP2.6 is the optimistic scenario (global warming slowdown). RCP4.5 and RCP6.0 are the second optimistic scenario and the second pessimistic scenario (the global warming rate remains the same), and RCP8.5 is the pessimistic scenario (increased global warming), and the future climate change scenarios were simulated based on this to determine the amount of change in the number of tourists to provide reference information of scientific views for forest park managers and planners.

Second, this study used the daily number of tourists and the daily climatic factors in the Huisun Forest Park to establish the regression model to predict the relationship between the climate factors and the number of tourists in the Huisun Forest Park, including the different climate change scenarios that may affect the number of tourists $[2,3,5-7,9,10]$.

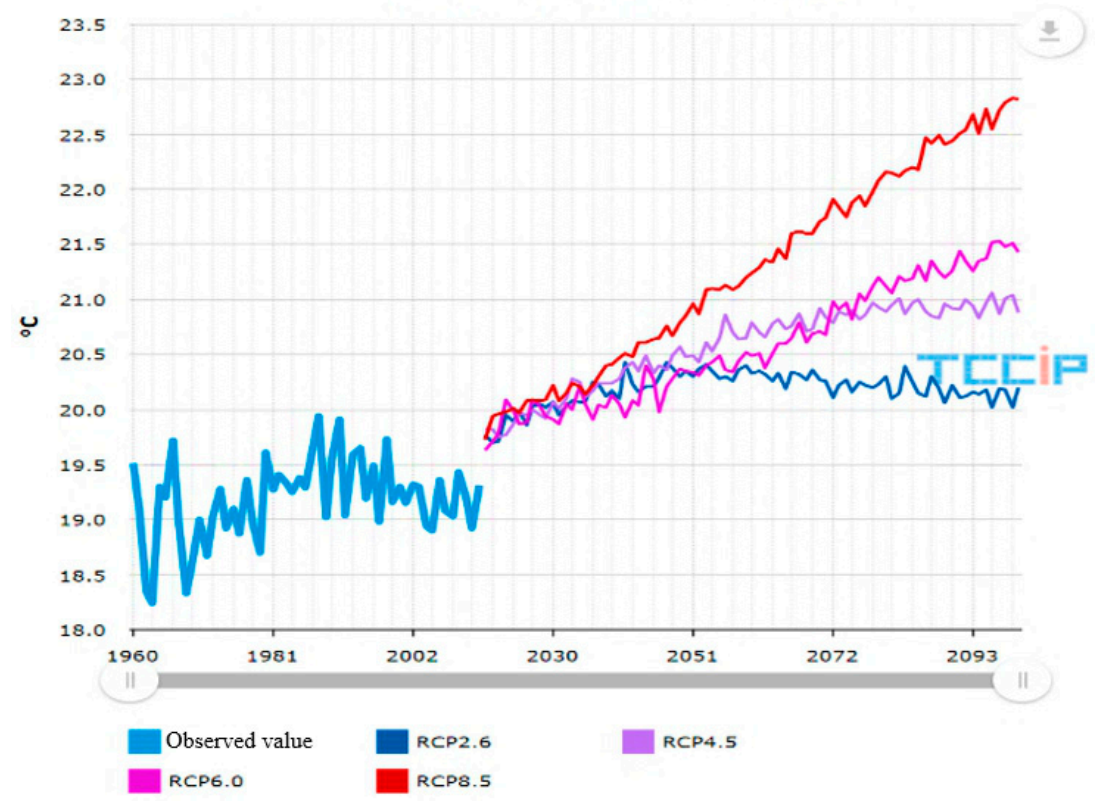

(a) Prediction of Temperature (2020-2100)

Figure 2. Cont. 


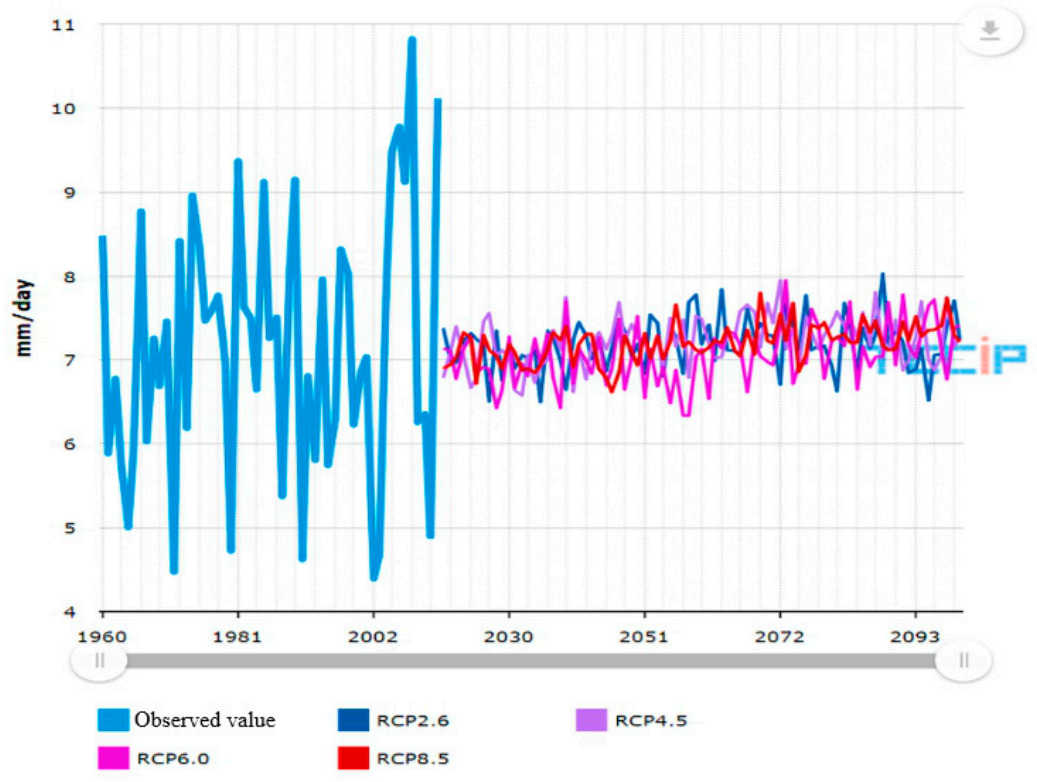

(b) Prediction of Precipitation (2020-2100)

Figure 2. Future temperature and precipitation predictions of four scenarios for Huisun Forest.

\subsection{Variables of Assessing Models}

\subsubsection{Temperature $\left({ }^{\circ} \mathrm{C}\right)(\mathrm{Tt})$}

This study has three variables in temperature, including the highest temperature, average temperature, and lowest temperature of the day. Each model selects one of the temperature variables to be substituted with a total of 791 sets of data between 11/2/2015 and 12/31/2017 provided by the meteorological observation station in Huisun Forest Park, with the data as shown in Figure 3. However, there are missing temperature data between 11/13/2015 and 1/20/2016, and between 1/17/2017 and $3 / 17 / 2017$. In order to solve this problem, this study used the weather data for January, February, March, November, and December of 2014-2017, using the total precipitation of the day, and the date used virtual variables to establish the regression equation, to estimate the missing temperature data.

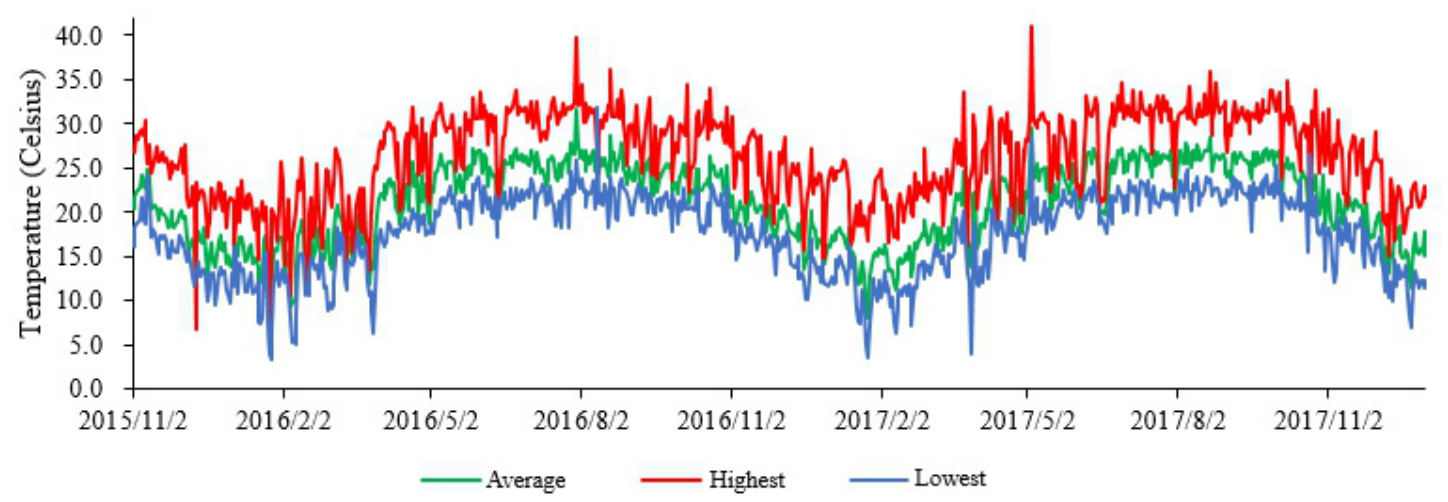

Figure 3. Temperature data for Huisun Forest Park (2015/11/2-2017/12/31). 


\subsubsection{Tourist Season}

This study divided the tourist seasons into three seasons according to the number of tourists: the peak season, second peak season, and off season, in order to establish a model for predicting the number of tourists $[5,13]$. Because this study used the daily number of tourists data between $11 / 2 / 2015$ and $12 / 31 / 2017$, this study defined the average monthly number of tourists of more than or equal to 16,500 persons in 2016-2017 as the peak season, and this study defined the peak season months as February, July, August, and October; the average monthly number of tourists of less than 16,500 persons and more than 13,000 persons in 2016-2017 as the second peak season, where the second peak season includes January, April, May, November, and December; and the average monthly number of tourists of less than 13,000 in 2016-2017 as the off season, where the off seasons includes March, June, and September.

\subsubsection{Relative Humidity (\%) (RHt)}

There are three variables in relative humidity, including the relative humidity at 9:00 of the day, relative humidity at 14:00 of the day, and the average relative humidity of the day. Each model selects one of the relative humidity variables to be substituted with a total of 791 sets of data between 11/2/2015 and 12/31/2017 provided by the station in Huisun Forest Park. However, there are missing data in relative humidity between $11 / 13 / 2015$ and $11 / 30 / 2015$, between $1 / 1 / 2016$ and 1/20/2016, and between $1 / 17 / 2017$ and $3 / 17 / 2017$. In order to solve this problem, this study used the weather data for January, February, March, November, and December of 2014-2017, using the total precipitation and temperature variables of the day (the average temperature of the day, the highest temperature of the day, and the lowest temperature of the day to select the regression equation highest $\mathrm{Adj}-R^{2}$ value) to establish the regression equation, to estimate the missing relative humidity data.

\subsubsection{Whether It Is Weekend (Wt) and Whether or Not There Are Consecutive National Holidays (Ht)}

This study set the weekend as a binary virtual variable: 0 is for Monday to Friday and 1 for Saturday and Sunday. Whether or not there are consecutive national holidays was set as a binary virtual variable: 0 is for no national holidays for more than three days, and 1 is for the national holidays of more than 3 days. The national holidays used for this study included New Year's Day, Lunar New Year, 228 Peace Memorial Day, Children and Qing Ming Festival, Dragon Boat Festival, Mid-Autumn Festival, and ROC National Day. The weekend consecutive holidays were set as the virtual variable of 1 , and non-weekend non-consecutive holidays as the virtual variable of 0 , which can take the impact of weekends and consecutive holidays into consideration.

\subsubsection{Whether There Is Natural Disaster Impact (Dt)}

This study set whether there is a natural disaster impact as binary virtual variables: 0 is for no natural disaster impact and 1 is for without natural disaster impact. The types of natural disasters include typhoon, heavy rain (this study defined its standard as the total precipitation of the day $\geq 30 \mathrm{~mm}$ ), which resulted in the situations that Nantou County Government announces the suspension of works and classes or the inability of tourists to reluctantly go to the Huisun Forest Park, such as Typhoon Nepartak, Typhoon Meranti, Typhoon Megi, and heavy rains that caused road landslide or caused suspension of works and classes.

\subsection{Samples}

This study divided the samples into all samples, weekend samples (only weekend samples were selected, excluding whether there are weekend variables), and no natural disaster samples on weekends (only weekends and no natural disasters were selected, excluding whether there are weekend variables and natural disaster impact variables). In short, there were a total of 3 regression models. 
- All Samples:

$$
Q t=\beta 1 T t+\beta 2 P t+\beta 3 R H t+\beta 4 W t+\beta 5 H t+\beta 6 D t,
$$

where $\mathrm{Qt}$ is the tourist count (persons per day) of the $\mathrm{tth}$ day; $\mathrm{Tt}$ is the temperature variable (Celsius) of the th day; $\mathrm{Pt}$ is the total precipitation ( $\mathrm{mm}$ per day) of the th day; $\mathrm{RHt}$ is the relative humidity variable (\%) of the tth day; $\mathrm{Wt}$ is the virtual variable of whether it is a weekend ( 0 is Monday through Friday, 1 is Saturday, Sunday) of the th day; $\mathrm{Ht}$ is the virtual variable of whether or not it is a national consecutive holiday ( 0 is not national consecutive holidays of more than three days, 1 is national consecutive holidays of more than three days) of the tth day; and $\mathrm{Dt}$ is the virtual variable of whether or not there is a natural disaster impact ( 0 is without natural disaster impact, 1 is with a natural disaster impact).

- Weekend Samples:

$$
\mathrm{Qt}=\beta 1 \mathrm{Tt}+\beta 2 \mathrm{Pt}+\beta 3 \mathrm{RH}+\beta 4 \mathrm{Ht}+\beta 5 \mathrm{Dt},
$$

where $\mathrm{Qt}$ is the tourist count (persons per day) of the tth day; $\mathrm{Tt}$ is the temperature variable (Celsius) of the th day; $\mathrm{Pt}$ is the total precipitation ( $\mathrm{mm}$ per day) of the tth day; RHt is the relative humidity variable $(\%)$ of the th day; $\mathrm{Ht}$ is the virtual variable of whether it is a national consecutive holiday $(0$ is not national consecutive holidays of more than three days, 1 is national consecutive holidays of more than three days) of the tth day; and Dt is the virtual variable of whether there is natural disaster impact ( 0 is without natural disaster impact, 1 is with natural disaster impact).

- Weekend without Natural Disaster Samples:

$$
Q t=\beta 1 \mathrm{Tt}+\beta 2 \mathrm{Pt}+\beta 3 \mathrm{RH}+\beta 4 \mathrm{Ht},
$$

where Qt is the tourist count (persons per day) of the tth day; $\mathrm{Tt}$ is the temperature variable (Celsius) of the tth day; $\mathrm{Pt}$ is the total precipitation ( $\mathrm{mm}$ per day) of the th day; RHt is the relative humidity variable (\%) of the tth day; and $\mathrm{Ht}$ is the virtual variable of whether it is the national consecutive holidays ( 0 is not national consecutive holidays of more than three days, 1 is a national consecutive holidays of more than three days) of the tth day.

\section{Results}

The natural factors explored in this study are the temperature of the day, total precipitation of the day, the relative humidity of the day, whether or not the threshold temperature is reached, and whether or not there is a natural disaster impact. The social factors include whether or not it is a weekend or whether or not there is a national holiday. This study incorporated two social variables of weekends and national consecutive holidays to effectively control some of the daily non-climate-induced changes. In order to establish the relationship between the weather and the number of tourists in the Huisun Forest Park, this study used the daily tourist count, temperature of the day, total precipitation of the day, and relative humidity of the day between 11/2/2015 and 12/31/2017 with a total of 791 sets of data provided by the Huisun Forest Park and the meteorological observation station in the park, respectively. 


\subsection{Results of Estimated Variables}

\subsubsection{Tourist Count}

The number of tourists can be regarded as a measure of the weather sensitivity and comfort of humans during recreational activities [29]. In this study, the number of tourists was used to measure the weather preference (temperature, precipitation) of the tourists. This study used the number of tourists daily data between 11/2/2015 and 12/31/2017 (Figure 4), with a total of 791 sets of data, provided by Huisun Forest Park.

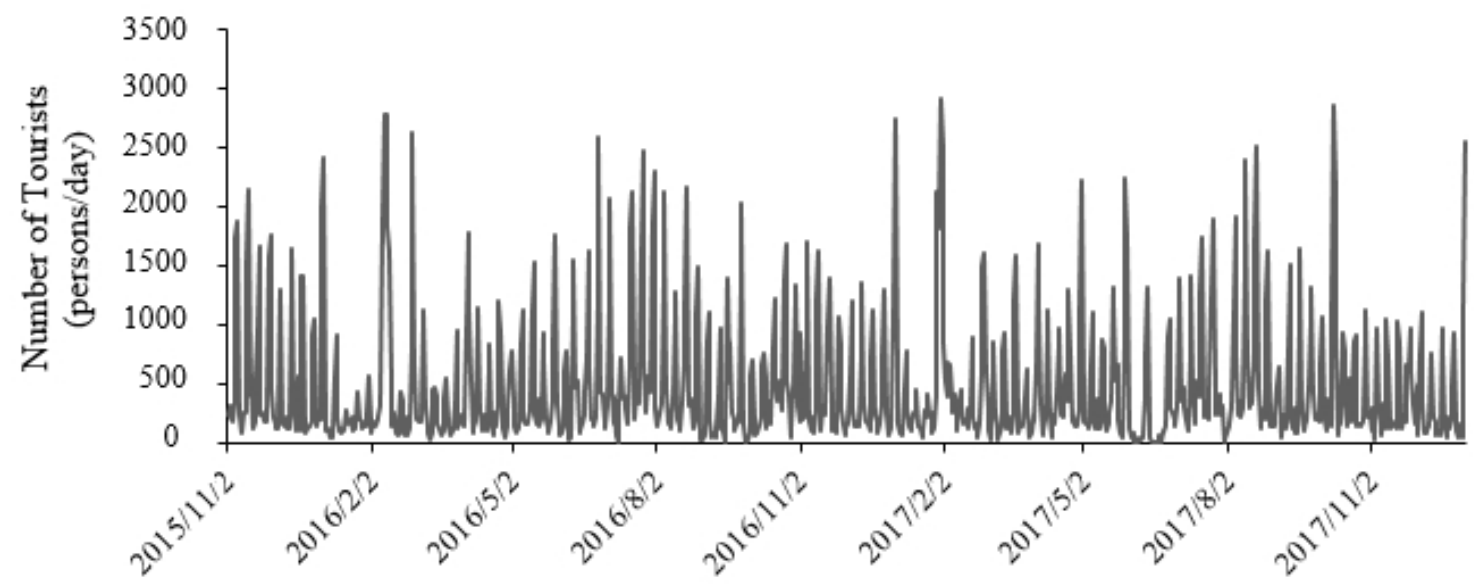

Figure 4. Huisun Forest Park 11/2/2015-12/31/2017 number of tourists data.

\subsubsection{Temperature}

Table 1 is the date and precipitation to estimate the $\mathrm{Adj}-R^{2}$ value of the temperature regression equation. It can be found that the value is $>0.9$, so it has a high explanatory power.

Table 1. Month and precipitation to estimate the adj- $R^{2}$ value of the temperature regression equation.

\begin{tabular}{lccccc}
\hline $\begin{array}{l}\text { Date and Precipitation to Estimate } \\
\text { the Adj- } \boldsymbol{R}^{\mathbf{2}} \text { Value of Temperature }\end{array}$ & January & February & March & November & December \\
\hline Average Temperature of the Day & 0.976 & 0.963 & 0.980 & 0.993 & 0.984 \\
Highest Temperature of the Day & 0.983 & 0.971 & 0.978 & 0.990 & 0.984 \\
Lowest Temperature of the Day & 0.929 & 0.933 & 0.959 & 0.987 & 0.970 \\
\hline
\end{tabular}

\subsubsection{Peak Season, Second Peak Season, Off Season}

Figure 5 shows the information of the monthly average number of tourists in Huisun Forest Park between 2016 and 2017. 


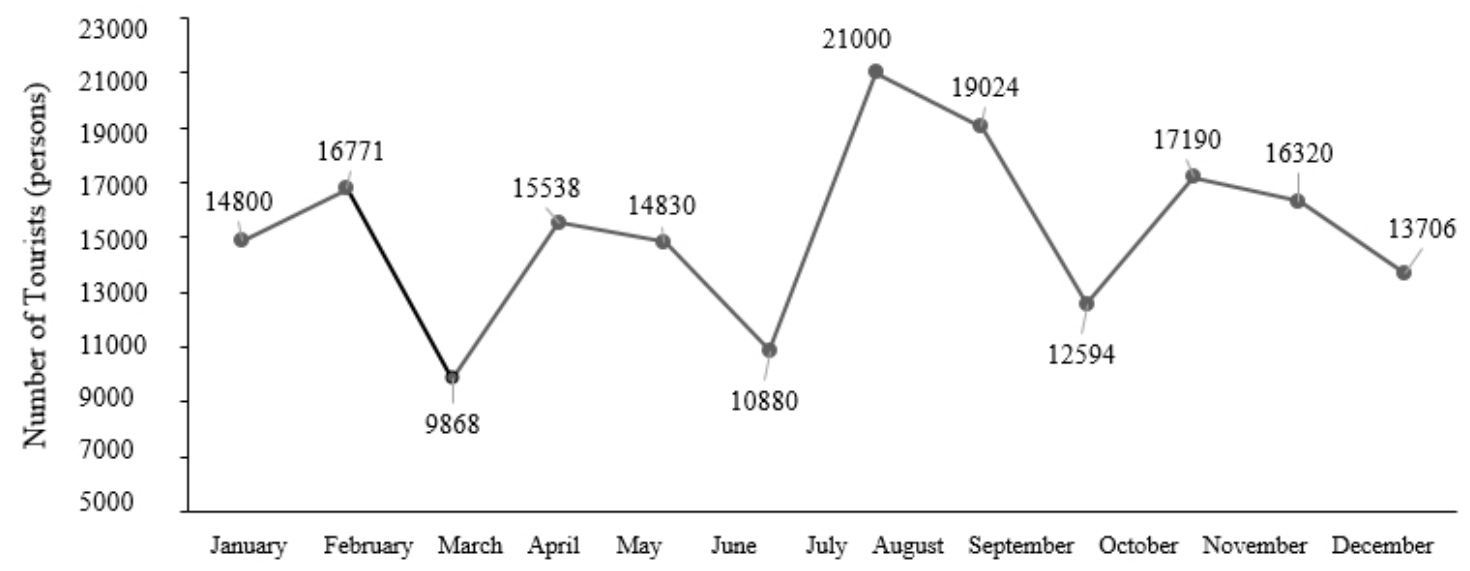

Figure 5. Huisun Forest Park monthly 2016-2017 average number of tourists.

\subsubsection{Threshold Temperature}

This study attempted to find the threshold temperature for the number of tourists in different tourist seasons. For this purpose, the one-way ANOVA was used to analyze the relationship between temperature and the number of tourists, and then to examine the turning temperature points in each season to find the threshold temperature. This approach used the ANOVA graph to find the threshold temperature: the number of tourists begins to show a negative correlation after reaching the turning point, which originally correlated to the temperature positively in the graph, and this turning point is the threshold temperature. However, after the samples of this study were done with ANOVA analysis, there was no significant turning point found related to the temperature and number of tourists; therefore, it is estimated that there is no threshold temperature in Huisun Forest Park, and this study excluded the threshold temperature variables in the regression analysis.

\subsubsection{Daily Total Precipitation (mm per Day) (Pt)}

The daily total precipitation is the sum of hourly precipitation accumulated for one day of time. The data is provided by the meteorological observation station in Huisun Forest Park. Figure 6 represents the Huisun Forest Park daily total precipitation data between 11/2/2015 and 12/31/2017. Figure 7 demonstrates the relationship between the number of tourists in the peak season, second peak season, and off season on the grouped total precipitation of the day. It can be found that the higher the total precipitation, the less the number of tourists, in general.

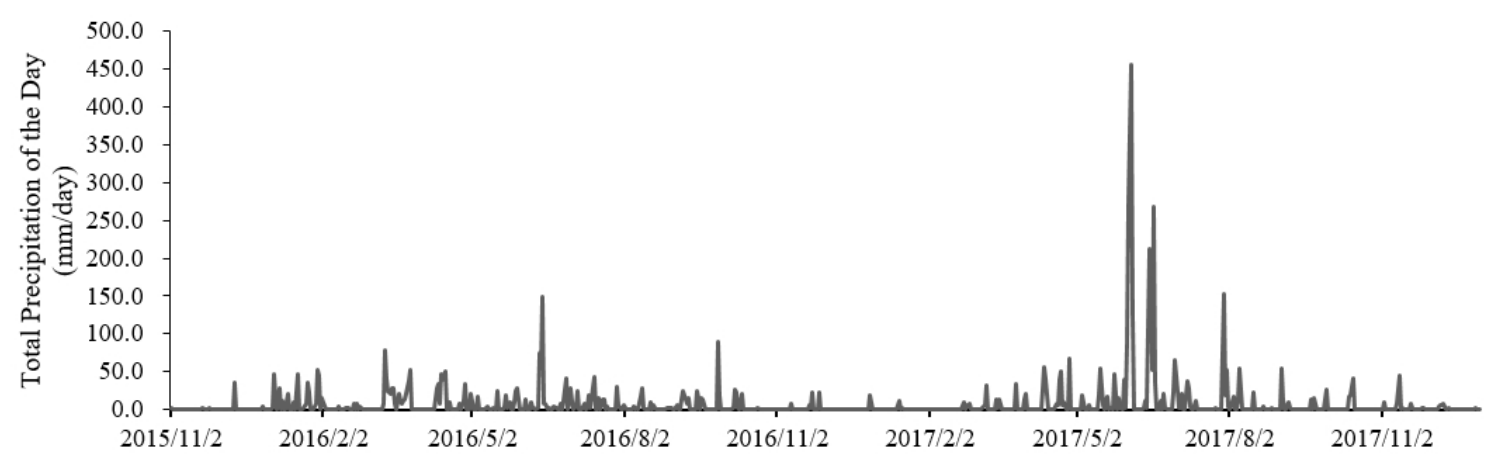

Figure 6. Huisun Forest Park precipitation data (2015/11/2-2017/12/31). 


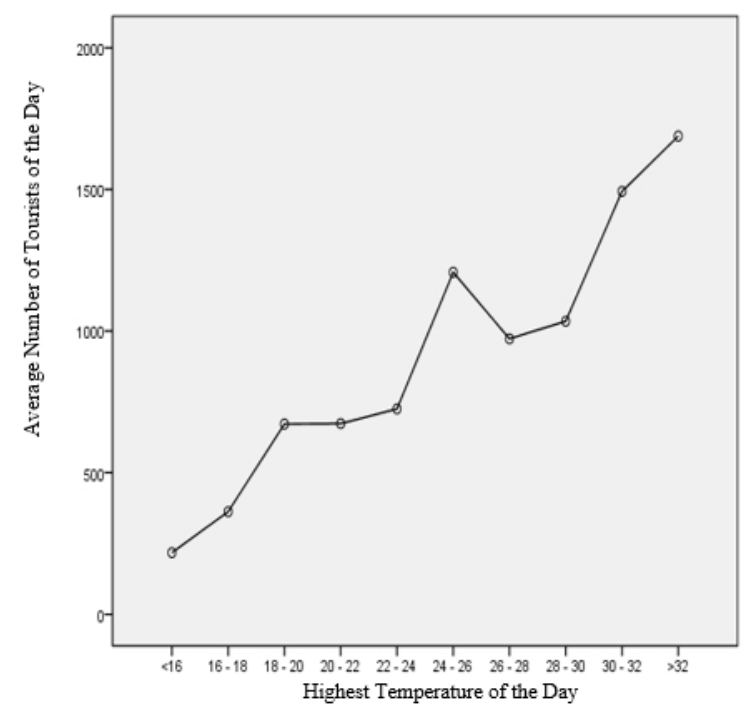

(a) Peak Season

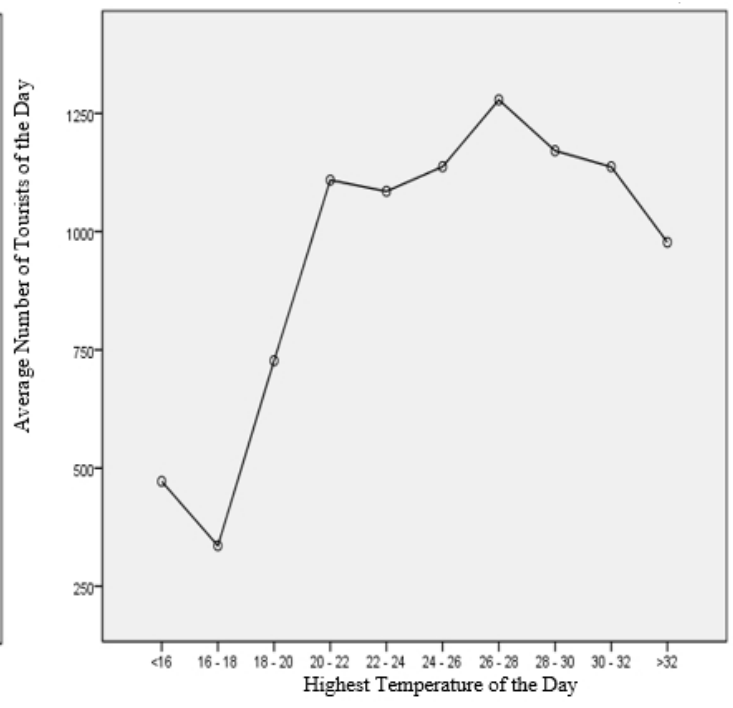

(b) Second Peak Season

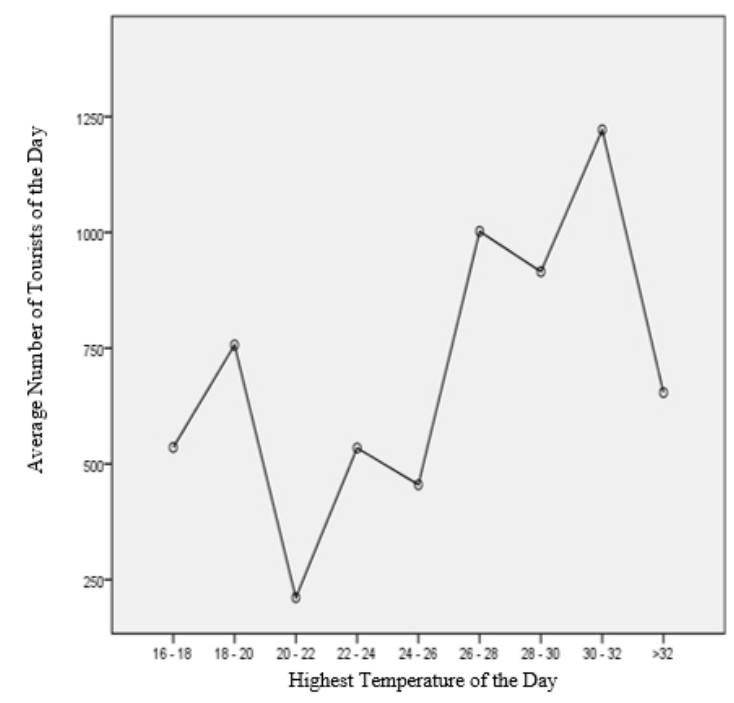

(c) Off Season

Figure 7. The relationship between the number of tourists in the peak season, second peak season, off season, and the grouped maximum temperature of the day.

\subsubsection{Relative Humidity}

Table 2 shows the temperature and precipitation to estimate the Adj- $R^{2}$ value of the relative humidity regression equation. It can be found that the value is $>0.9$, so it has high explanatory power. Figure 8 shows the relationship between the number of tourists in the peak season, second peak season, off season, and the grouped total precipitation of the day, and the grouped average relative humidity of the day, respectively. It can be found that the higher the relative humidity, the less the number of tourists, in general. 
Table 2. Temperature and precipitation to estimate the adj- $R^{2}$ value of the regression equation.

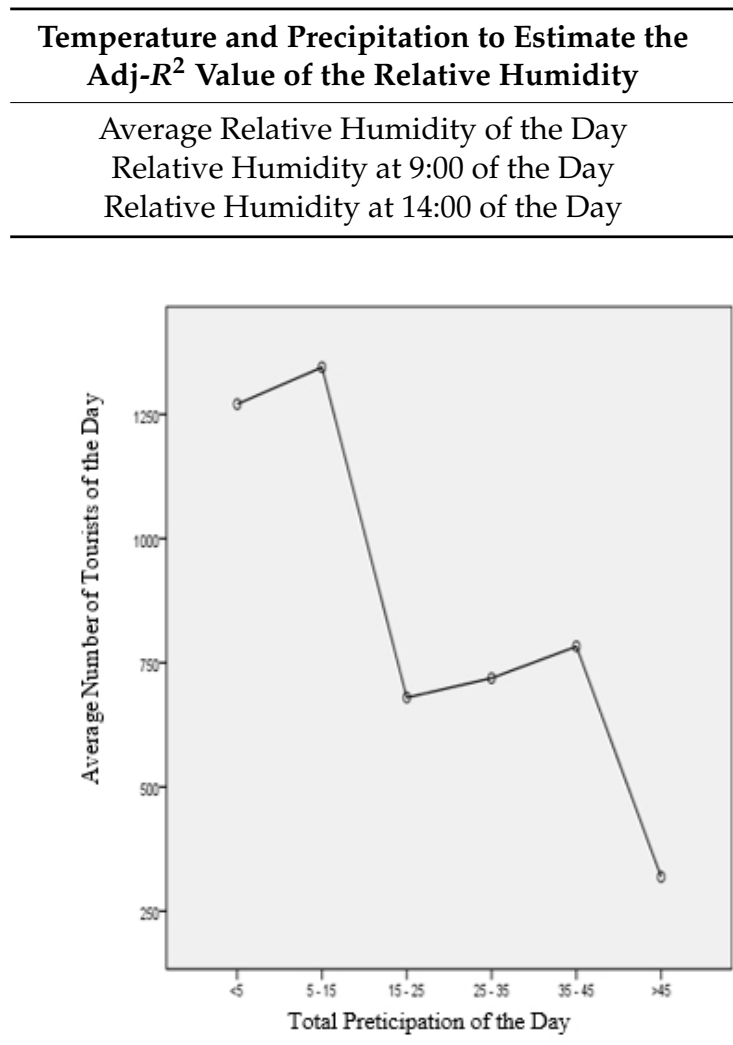

(a) Peak Season

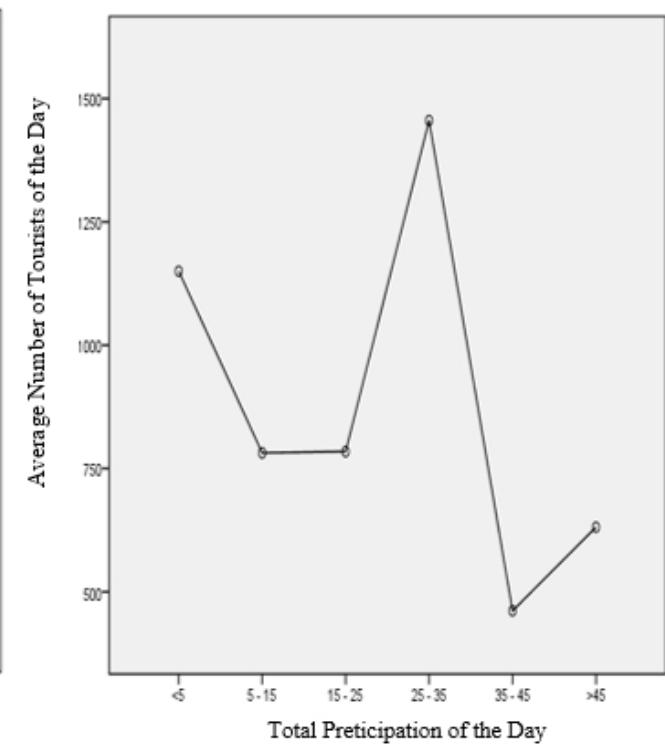

(b) Second Peak Season

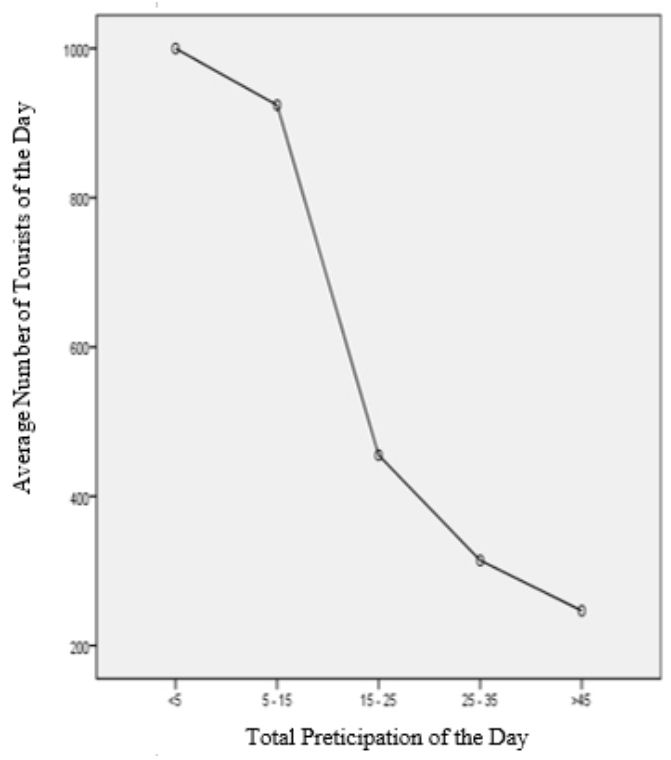

(c) Off Season

Figure 8. The relationship between the number of tourists in the peak season, second peak season, and off season on the grouped total precipitation of the day.

\subsubsection{Construction of Empirical Regression Model}

According to the number of tourists, this study divided the tourist seasons into at least the tourism peak season (February, July, August, October), the second peak season (January, April, May, November, 
December), and off season (March, June, September); all these three seasons have all samples, weekend samples (only weekend samples were selected, excluding whether or not it is a weekend variable) and weekend without disaster samples (only weekends without a natural disaster samples were selected, excluding whether or not it is weekend variable and whether or not there is natural disaster impact), with a total of 3 (peak season, second peak season, off season) * 3 (all samples, weekend samples, weekend without natural disaster samples) for a total of 9 regression models (Figure 9). In addition, each model has three temperature variables: the highest temperature of the day, average temperature of the day, and the lowest temperature of the day can be selected; and the relative humidity variables have the relative humidity at 9:00 of the day, relative humidity at 14:00 of the day, and average relative humidity of the day, thus three relative humidity variables can be selected. Therefore, thee three temperature variables and three relative humidity variables were substituted into each model, so there were 3 models (the highest, average, and minimum temperatures of the day) * $3(9: 00,14: 00$, average relative humidity) for the Adj- $R^{2}$ values of a total of 9 models, as shown in Tables 3-11, to select the highest Adj- $R^{2}$ value as the selected temperature and relative humidity variables for the model.

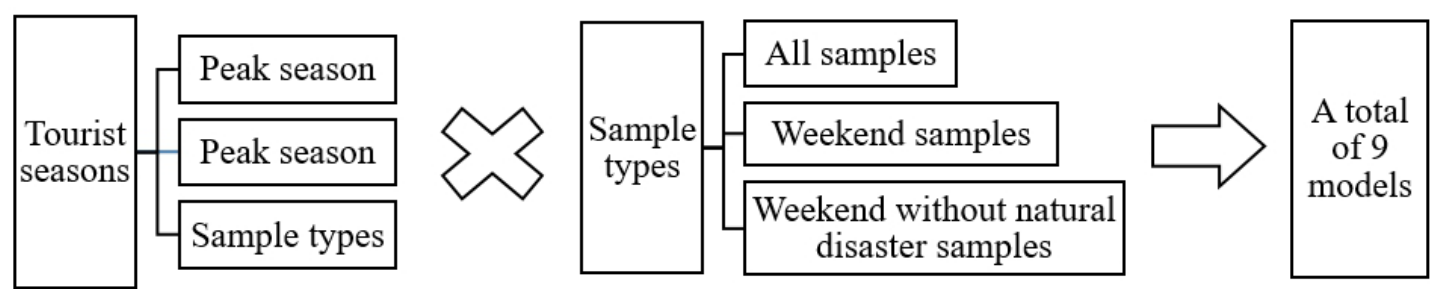

Figure 9. Explanation of a total of 9 models for the tourist seasons and sample types.

Table 3. Summary for the Adj- $R^{2}$ value of different regression models (peak season all samples).

\begin{tabular}{clccc}
\hline \multirow{2}{*}{ Peak Season All Samples } & \multicolumn{2}{c}{ Relative Humidity Variable } \\
\cline { 3 - 5 } & $\begin{array}{c}\mathbf{9 : 0 0} \text { Relative } \\
\text { Humidity }\end{array}$ & $\begin{array}{c}\text { 14:00 Relative } \\
\text { Humidity }\end{array}$ & $\begin{array}{c}\text { Average Relative } \\
\text { Humidity }\end{array}$ \\
\hline \multirow{2}{*}{ Temperature } & Highest Temperature of the Day & 0.765 & 0.763 & 0.762 \\
Variable & Average Temperature of the Day & 0.760 & 0.762 & 0.758 \\
& Lowest Temperature of the Day & 0.747 & 0.749 & 0.745 \\
\hline
\end{tabular}

Note 1: These are Adj- $R^{2}$ values obtained from the nine regression models in Table. Note 2: The regression model of this study considers multiple variables, among them the temperature-related variables including the highest temperature of the day, the average temperature of the day, and the lowest temperature of the day; the relative humidity-related variables include the 9:00 relative humidity of the day, the 14:00 relative humidity of the day, and the average relative humidity of the day; this study selected the temperature variable and relative humidity variable with the highest $\mathrm{Adj}-R^{2}$ value, which is presented in gray background.

Table 4. Summary for the Adj- $R^{2}$ value of different regression models (second peak season weekend without natural disaster samples).

\begin{tabular}{|c|c|c|c|c|}
\hline \multirow{2}{*}{\multicolumn{2}{|c|}{$\begin{array}{l}\text { Off Season Weekend without Natural } \\
\text { Disaster Samples }\end{array}$}} & \multicolumn{3}{|c|}{ Relative Humidity Variable } \\
\hline & & $\begin{array}{l}\text { 9:00 Relative } \\
\text { Humidity }\end{array}$ & $\begin{array}{l}\text { 14:00 Relative } \\
\text { Humidity }\end{array}$ & $\begin{array}{l}\text { Average Relative } \\
\text { Humidity }\end{array}$ \\
\hline \multirow{3}{*}{$\begin{array}{l}\text { Temperature } \\
\text { Variable }\end{array}$} & Highest Temperature of the Day & 0.862 & 0.849 & 0.848 \\
\hline & Average Temperature of the Day & 0.861 & 0.844 & 0.841 \\
\hline & Lowest Temperature of the Day & 0.834 & 0.831 & 0.828 \\
\hline
\end{tabular}


Table 5. Summary of the estimated results for the tourist count impact.

\begin{tabular}{|c|c|c|c|c|c|c|c|c|c|}
\hline \multirow[b]{2}{*}{ Variable } & \multicolumn{3}{|c|}{ Peak Season } & \multicolumn{3}{|c|}{ Second Peak Season } & \multicolumn{3}{|c|}{ Off Season } \\
\hline & All Samples & $\begin{array}{l}\text { Weekend } \\
\text { Samples }\end{array}$ & $\begin{array}{c}\text { Weekend } \\
\text { without Natural } \\
\text { Disaster Samples }\end{array}$ & All Samples & $\begin{array}{l}\text { Weekend } \\
\text { Samples }\end{array}$ & $\begin{array}{c}\text { Weekend } \\
\text { without Natural } \\
\text { Disaster Samples }\end{array}$ & $\begin{array}{c}\text { All } \\
\text { Samples }\end{array}$ & $\begin{array}{l}\text { Weekend } \\
\text { Samples }\end{array}$ & $\begin{array}{c}\text { Weekend } \\
\text { without Natural } \\
\text { Disaster Samples }\end{array}$ \\
\hline $\begin{array}{c}\text { Highest Temperature of } \\
\text { the Day }\end{array}$ & $29.350^{* * *}$ & - & - & $11.459^{* * *}$ & $33.476^{* * *}$ & $31.733^{* * *}$ & $16.338^{* * *}$ & $53.324^{* * *}$ & $65.557^{* * *}$ \\
\hline $\begin{array}{c}\text { Average Temperature } \\
\text { of the Day }\end{array}$ & - & $95.267^{* * *}$ & $94.467^{* * *}$ & - & - & - & - & - & - \\
\hline 9:00 Relative Humidity & $-6.178^{* * *}$ & - & - & - & 2.529 & 2.981 & $-2.966 *$ & $-6.337^{*}$ & $-10.928 *$ \\
\hline $\begin{array}{l}\text { 14:00 Relative } \\
\text { Humidity }\end{array}$ & - & $-13.96^{* * *}$ & $-13.349^{* * *}$ & -0.714 & - & - & - & - & - \\
\hline Total Precipitation & -1.428 & 0.636 & -8.890 & -4.244 & -7.309 & -8.374 & -0.964 & -0.794 & 16.678 \\
\hline $\begin{array}{l}\text { Total Precipitation } \\
\text { Whether or not it is }\end{array}$ & $791.529 * * *$ & - & - & $771.438^{* * *}$ & - & - & $672.596^{* * *}$ & - & - \\
\hline $\begin{array}{c}\text { Consecutive National } \\
\text { Holidays }\end{array}$ & $767.781^{* * *}$ & $452.434^{* *}$ & $451.363 * *$ & $796.700 * * *$ & $634.687^{* * *}$ & $693.776^{* * *}$ & $380.278^{* * *}$ & 67.118 & -171.322 \\
\hline $\begin{array}{c}\text { Whether or not there is } \\
\text { Natural Disaster } \\
\text { Impact }\end{array}$ & -319.536 & $-765.784 *$ & - & 3.075 & -93.028 & - & -106.208 & -231.101 & - \\
\hline Adj- $R^{2}$ & 0.765 & 0.888 & 0.893 & 0.810 & 0.860 & 0.867 & 0.753 & 0.840 & 0.862 \\
\hline Durbin-Watson & 1.384 & 2.359 & 2.405 & 1.740 & 1.926 & 1.909 & 1.677 & 2.090 & 1.807 \\
\hline
\end{tabular}

Note 1: Gray background indicates significance, ${ }^{*}$ is significance $<0.05$; ${ }^{* *}$ is significance $<0.01$; ${ }^{* * *}$ is significance $<0.001$. Note 2 : The model variables selected in this study are the variable models with the highest Adj- $R^{2}$ value of each model, as described in Tables 3-11.

Table 6. Peak season number of tourists increase (persons per season) and increate rate (\%).

\begin{tabular}{|c|c|c|c|c|c|c|c|c|}
\hline \multirow{2}{*}{$\begin{array}{l}\Delta \text { Peak Season Number of Tourists (Season) } \\
+0.5^{\circ} \mathrm{C}\end{array}$} & \multicolumn{2}{|c|}{$+\mathbf{1 0} \%$ Precipitation } & \multicolumn{2}{|c|}{$+5 \%$ Precipitation } & \multicolumn{2}{|c|}{$-5 \%$ Precipitation } & \multicolumn{2}{|c|}{$-10 \%$ Precipitation } \\
\hline & 1653 & $0.94 \%$ & 1716 & $0.97 \%$ & 1842 & $1.05 \%$ & 1905 & $1.08 \%$ \\
\hline$+1.0^{\circ} \mathrm{C}$ & 3433 & $1.95 \%$ & 3496 & $1.98 \%$ & 3622 & $2.06 \%$ & 3685 & $2.09 \%$ \\
\hline$+1.5^{\circ} \mathrm{C}$ & 5212 & $2.96 \%$ & 5275 & $2.99 \%$ & 5401 & $3.06 \%$ & 5464 & $3.10 \%$ \\
\hline$+2.0^{\circ} \mathrm{C}$ & 6991 & $3.97 \%$ & 7054 & $4.00 \%$ & 7180 & $4.07 \%$ & 7243 & $4.11 \%$ \\
\hline$+2.5^{\circ} \mathrm{C}$ & 8771 & $4.98 \%$ & 8834 & $5.01 \%$ & 8960 & $5.08 \%$ & 9023 & $5.12 \%$ \\
\hline$+3.0^{\circ} \mathrm{C}$ & 10,550 & $5.99 \%$ & 10,613 & $6.02 \%$ & 10,739 & $6.09 \%$ & 10,802 & $6.13 \%$ \\
\hline$+3.5^{\circ} \mathrm{C}$ & 12,330 & $7.00 \%$ & 12,392 & $7.03 \%$ & 12,518 & $7.10 \%$ & 12,581 & $7.14 \%$ \\
\hline
\end{tabular}


Table 7. Second peak season number of tourists increase (persons per season) and increate rate (\%).

\begin{tabular}{|c|c|c|c|c|c|c|c|c|}
\hline \multirow{2}{*}{$\begin{array}{l}\Delta \text { Second Peak Season Number of Tourists (Season) } \\
+0.5^{\circ} \mathrm{C}\end{array}$} & \multicolumn{2}{|c|}{$+10 \%$ Precipitation } & \multicolumn{2}{|c|}{$+5 \%$ Precipitation } & \multicolumn{2}{|c|}{$-5 \%$ Precipitation } & \multicolumn{2}{|c|}{$-10 \%$ Precipitation } \\
\hline & 404 & $0.23 \%$ & 641 & $0.36 \%$ & 1113 & $0.63 \%$ & 1349 & $0.77 \%$ \\
\hline$+1.0^{\circ} \mathrm{C}$ & 1281 & $0.73 \%$ & 1517 & $0.86 \%$ & 1989 & $1.13 \%$ & 2225 & $1.26 \%$ \\
\hline$+1.5^{\circ} \mathrm{C}$ & 2158 & $1.22 \%$ & 2394 & $1.36 \%$ & 2866 & $1.63 \%$ & 3102 & $1.76 \%$ \\
\hline$+2.0^{\circ} \mathrm{C}$ & 3034 & $1.72 \%$ & 3270 & $1.86 \%$ & 3743 & $2.12 \%$ & 3979 & $2.26 \%$ \\
\hline$+2.5^{\circ} \mathrm{C}$ & 3911 & $2.22 \%$ & 4147 & $2.35 \%$ & 4619 & $2.62 \%$ & 4855 & $2.76 \%$ \\
\hline$+3.0^{\circ} \mathrm{C}$ & 4788 & $2.72 \%$ & 5024 & $2.85 \%$ & 5496 & $3.12 \%$ & 5732 & $3.25 \%$ \\
\hline$+3.5^{\circ} \mathrm{C}$ & 5664 & $3.21 \%$ & 5900 & $3.35 \%$ & 6372 & $3.62 \%$ & 6608 & $3.75 \%$ \\
\hline
\end{tabular}

Table 8. Off season number of tourists increase (persons per season) and increate rate (\%).

\begin{tabular}{|c|c|c|c|c|c|c|c|c|}
\hline \multirow{2}{*}{$\begin{array}{l}\Delta \text { Off Season Number of Tourists (Season) } \\
+0.5^{\circ} \mathrm{C}\end{array}$} & \multicolumn{2}{|c|}{$+10 \%$ Precipitation } & \multicolumn{2}{|c|}{$+5 \%$ Precipitation } & \multicolumn{2}{|c|}{$-5 \%$ Precipitation } & \multicolumn{2}{|c|}{$-10 \%$ Precipitation } \\
\hline & 680 & $0.39 \%$ & 711 & $0.40 \%$ & 775 & $0.44 \%$ & 807 & $0.46 \%$ \\
\hline$+1.0^{\circ} \mathrm{C}$ & 1423 & $0.81 \%$ & 1455 & $0.83 \%$ & 1519 & $0.86 \%$ & 1551 & $0.88 \%$ \\
\hline$+1.5^{\circ} \mathrm{C}$ & 2166 & $1.23 \%$ & 2198 & $1.25 \%$ & 2262 & $1.28 \%$ & 2294 & $1.30 \%$ \\
\hline$+2.5^{\circ} \mathrm{C}$ & 3653 & $2.07 \%$ & 3685 & $2.09 \%$ & 3749 & $2.13 \%$ & 3781 & $2.15 \%$ \\
\hline$+3.0^{\circ} \mathrm{C}$ & 4396 & $2.49 \%$ & 4428 & $2.51 \%$ & 4492 & $2.55 \%$ & 4524 & $2.57 \%$ \\
\hline$+3.5^{\circ} \mathrm{C}$ & 5140 & $2.92 \%$ & 5172 & $2.93 \%$ & 5236 & $2.97 \%$ & 5267 & $2.99 \%$ \\
\hline
\end{tabular}

Table 9. Number of tourists increase in one year (persons per season) and increate rate (\%).

\begin{tabular}{|c|c|c|c|c|c|c|c|c|}
\hline \multirow{2}{*}{$\begin{array}{l}\Delta \text { Number of Tourists in One Year (Year) } \\
+0.5^{\circ} \mathrm{C}\end{array}$} & \multicolumn{2}{|c|}{$+10 \%$ Precipitation } & \multicolumn{2}{|c|}{$+5 \%$ Precipitation } & \multicolumn{2}{|c|}{$-5 \%$ Precipitation } & \multicolumn{2}{|c|}{$-10 \%$ Precipitation } \\
\hline & 2737 & $1.55 \%$ & 3068 & $1.74 \%$ & 3730 & $2.12 \%$ & 4061 & $2.30 \%$ \\
\hline$+1.0{ }^{\circ} \mathrm{C}$ & 6137 & $3.48 \%$ & 6468 & $3.67 \%$ & 7130 & $4.05 \%$ & 7461 & $4.23 \%$ \\
\hline$+1.5^{\circ} \mathrm{C}$ & 9536 & $5.41 \%$ & 9867 & $5.60 \%$ & 10,529 & $5.98 \%$ & 10,860 & $6.16 \%$ \\
\hline$+2.0^{\circ} \mathrm{C}$ & 12,935 & $7.34 \%$ & 13,266 & $7.53 \%$ & 13,928 & $7.90 \%$ & 14,259 & $8.09 \%$ \\
\hline$+2.5^{\circ} \mathrm{C}$ & 16,335 & $9.27 \%$ & 16,666 & $9.46 \%$ & 17,328 & $9.83 \%$ & 17,659 & $10.02 \%$ \\
\hline$+3.0^{\circ} \mathrm{C}$ & 19,734 & $11.20 \%$ & 20,065 & $11.39 \%$ & 20,727 & $11.76 \%$ & 21,058 & $11.95 \%$ \\
\hline$+3.5^{\circ} \mathrm{C}$ & 23,133 & $13.13 \%$ & 23,464 & $13.32 \%$ & 24,126 & $13.69 \%$ & 24,457 & $13.88 \%$ \\
\hline
\end{tabular}


Table 10. Peak season number of weekend tourists increase (persons per season) and increate rate (\%).

\begin{tabular}{|c|c|c|c|c|c|c|c|c|}
\hline \multirow{2}{*}{$\begin{array}{l}\Delta \text { Peak Season Weekend Number of Tourists (Season) } \\
+0.5^{\circ} \mathrm{C}\end{array}$} & \multicolumn{2}{|c|}{$+10 \%$ Precipitation } & \multicolumn{2}{|c|}{$+5 \%$ Precipitation } & \multicolumn{2}{|c|}{$-5 \%$ Precipitation } & \multicolumn{2}{|c|}{$-10 \%$ Precipitation } \\
\hline & 1539 & $0.87 \%$ & 1532 & $0.87 \%$ & 1517 & $0.86 \%$ & 1509 & $0.86 \%$ \\
\hline$+1.0^{\circ} \mathrm{C}$ & 3063 & $1.74 \%$ & 3056 & $1.73 \%$ & 3041 & $1.73 \%$ & 3034 & $1.72 \%$ \\
\hline$+1.5^{\circ} \mathrm{C}$ & 4588 & $2.60 \%$ & 4580 & $2.60 \%$ & 4565 & $2.59 \%$ & 4558 & $2.59 \%$ \\
\hline$+2.0^{\circ} \mathrm{C}$ & 6112 & $3.47 \%$ & 6104 & $3.46 \%$ & 6090 & $3.46 \%$ & 6082 & $3.45 \%$ \\
\hline$+2.5^{\circ} \mathrm{C}$ & 7636 & $4.33 \%$ & 7629 & $4.33 \%$ & 7614 & $4.32 \%$ & 7607 & $4.32 \%$ \\
\hline$+3.0^{\circ} \mathrm{C}$ & 9160 & $5.20 \%$ & 9153 & $5.19 \%$ & 9138 & $5.19 \%$ & 9131 & $5.18 \%$ \\
\hline$+3.5^{\circ} \mathrm{C}$ & 10,685 & $6.06 \%$ & 10,677 & $6.06 \%$ & 10,663 & $6.05 \%$ & 10,655 & $6.05 \%$ \\
\hline
\end{tabular}

Table 11. Second peak season number of weekend tourists increase (persons per season) and increate rate (\%).

\begin{tabular}{|c|c|c|c|c|c|c|c|c|}
\hline \multirow{2}{*}{$\begin{array}{l}\Delta \text { Second Peak Season Weekend Number of Tourists (Season) } \\
+0.5^{\circ} \mathrm{C}\end{array}$} & \multicolumn{2}{|c|}{$+10 \%$ Precipitation } & \multicolumn{2}{|c|}{$+5 \%$ Precipitation } & \multicolumn{2}{|c|}{$-5 \%$ Precipitation } & \multicolumn{2}{|c|}{$-10 \%$ Precipitation } \\
\hline & 457 & $0.26 \%$ & 563 & $0.32 \%$ & 776 & $0.44 \%$ & 882 & $0.50 \%$ \\
\hline$+1.0^{\circ} \mathrm{C}$ & 1126 & $0.64 \%$ & 1233 & $0.70 \%$ & 1445 & $0.82 \%$ & 1552 & $0.88 \%$ \\
\hline$+1.5^{\circ} \mathrm{C}$ & 1796 & $1.02 \%$ & 1902 & $1.08 \%$ & 2115 & $1.20 \%$ & 2221 & $1.26 \%$ \\
\hline$+2.0^{\circ} \mathrm{C}$ & 2465 & $1.40 \%$ & 2572 & $1.46 \%$ & 2784 & $1.58 \%$ & 2891 & $1.64 \%$ \\
\hline$+2.5^{\circ} \mathrm{C}$ & 3135 & $1.78 \%$ & 3241 & $1.84 \%$ & 3454 & $1.96 \%$ & 3560 & $2.02 \%$ \\
\hline$+3.0^{\circ} \mathrm{C}$ & 3805 & $2.16 \%$ & 3911 & $2.22 \%$ & 4123 & $2.34 \%$ & 4230 & $2.40 \%$ \\
\hline$+3.5^{\circ} \mathrm{C}$ & 4474 & $2.54 \%$ & 4580 & $2.60 \%$ & 4793 & $2.72 \%$ & 4899 & $2.78 \%$ \\
\hline
\end{tabular}




\subsection{Results of the Forecast Model of Tourists Count}

\subsubsection{Peak Season All Samples}

Table 3 represents the summary for the $\operatorname{Adj}-R^{2}$ values of nine models. It can be seen that the $\operatorname{Adj}-R^{2}$ value of the highest temperature of the day and the 9:00 relative humidity model is the highest; therefore, the highest temperature of the day and the 9:00 relative humidity were selected as the temperature variable and the relative humidity variable.

Therefore, the regression model setting of the peak season all samples is as follows:

$$
\mathrm{Qt}=\beta 1 \mathrm{Ttmax}+\beta 2 \mathrm{Pt}+\beta 3 \mathrm{RH} \mathrm{t} 9+\beta 4 \mathrm{Wt}+\beta 5 \mathrm{Ht}+\beta 6 \mathrm{Dt},
$$

where Qt is the tourist count (persons per day) of the tth day; Ttmax is the highest temperature (Celsius) of the tth day; $\mathrm{Pt}$ is the total precipitation (mm per day) of the th day; RHt9 is the 9:00 relative humidity $(\%)$ of the th day; $\mathrm{Wt}$ is the virtual variable of whether it is a weekend ( 0 is Monday through Friday, 1 is Saturday, Sunday) of the th day; $\mathrm{Ht}$ is the virtual variable of whether it is a national consecutive holiday ( 0 is not national consecutive holidays of more than three days, 1 is national consecutive holidays of more than three days) of the tth day; and Dt is the virtual variable whether there is natural disaster impact ( 0 is without natural disaster impact, 1 is with natural disaster impact).

\subsubsection{Off Season Weekend without Natural Disaster Samples}

Table 4 is the Adj- $R^{2}$ values of those 9 models, where it can be seen that the Adj- $R^{2}$ value of the highest temperature of the day and the 9:00 relative humidity model is the highest. Therefore, the highest temperature of the day and the 9:00 relative humidity were selected as the temperature variable and the relative humidity variable. Qt is the tourist count (persons per day) of the th day; Ttmax is the highest temperature (Celsius) of the tth day; $\mathrm{Pt}$ is the total precipitation (mm per day) of the tth day; RHt9 is the 9:00 relative humidity (\%) of the th day; and Ht is the virtual variable of whether it is a consecutive national holiday ( 0 is not consecutive national holidays of more than three days, 1 is consecutive national holidays of more than three days).

Therefore, the regression model setting of the off season weekend without a natural disaster samples is as follows:

$$
\mathrm{Qt}=\beta 1 \mathrm{Ttmax}+\beta 2 \mathrm{Pt}+\beta 3 \mathrm{RH} \mathrm{t} 9+\beta 4 \mathrm{Ht},
$$

where Qt is the tourist count (persons per day) of the tth day; Ttmax is the highest temperature (Celsius) of the th day; $\mathrm{Pt}$ is the total precipitation (mm per day) of the th day; $\mathrm{RH}+9$ is the 9:00 relative humidity $(\%)$ of the th day; and $\mathrm{Ht}$ is the virtual variable of whether it is a consecutive national holiday (0 is not consecutive national consecutive holidays of more than three days, 1 is consecutive national holidays of more than three days) of the th day.

\subsection{Simulation Scenarios of Climate Change in Taiwan}

This study compared the annual temperature and precipitation data of 2020-2100 [20] with the average temperature and precipitation of 30 years in the recent past (1980-2012) [20]. Specifically, this study calculated the range of average temperature and precipitation changes by assuming that the highest temperature change for a given day was the same as the average temperature change for that day. Using each day as a measure of time, this study simulated a future climate change scenario. The temperature was measured based on the average temperatures between 1980 and 2012, generating seven change scenarios with increases of $0.5,1,1.5,2,2.5,3$, and $3.5^{\circ} \mathrm{C}$ in the highest temperatures, respectively. The precipitation was estimated based on the average daily precipitation between 1980 and 2012, generating four change scenarios of $+10 \%,+5 \%,-5 \%$, and $-10 \%$ in total precipitation for the day. Finally, this study generated $7 \times 4$ scenarios, for a total of 28 climate change scenarios, by combining the change scenarios of the highest temperature of the day with the total precipitation of the day. 
Table 5 is the results of all samples, weekend samples, and weekend samples without natural disaster sample models of the peak season, second peak season, and off season, where the independent variables include the highest temperature of the day, average temperature of the day, 9:00 relative humidity of the day, 14:00 relative humidity of the day, total precipitation of the day, whether or not it is a weekend, whether or not it is a consecutive national holiday, whether or not there is a natural disaster impact; and the dependent variable is the tourist count of the day. The results of this study show that the Adj- $R^{2}$ values of every regression equation are $>0.75$, where all have high explanatory power. The temperature variables of all regression models, regardless of whether or not it is the highest temperature of the day or the average temperature of the day, are ${ }^{* * *}$ significant; whether or not it is a weekend variable in the regression models of the peak season all samples, second peak season all samples, and off season all samples are ${ }^{* * *}$ significant in the regression models; whether it is a consecutive national holiday variables, except for the regression models of off season weekend samples and off season weekend without natural disaster samples, are not significant, while all other models are ${ }^{* * *}$ significant; and whether or not there is a natural disaster variables in the regression models of peak season weekend samples are * significant. The results of this study show that the social factor impact variables (weekends, consecutive national holidays) on the number of tourists $>$ natural factor variables (temperature, relative humidity, precipitation), the same as the results of Hadwen et al. (2011) [3], and the determinants of sub-tropical regions are social factors (weekend, national consecutive holidays).

Table 5 can be used to understand the weather sensitivity of each season. With the peak season the same as the off season, both the temperature variables and relative humidity variables have significant impacts, and the precipitation variables are not significant; the second peak season only has a significant impact on the temperature variables, while the relative humidity variables and precipitation variables are not significant. It can be seen from Table 5 which climatic factors have the most impact on the tourist count. In all nine models, the temperature variable coefficient value is larger than the relative humidity variable coefficient value and the precipitation variable coefficient value; in other words, the impact of temperature change on the tourist count is greater than the changes in relative humidity and precipitation. There are changes in the impact of each climatic factor under different seasons: the temperature variable is the climatic factor with the most impact in three seasons, and its significance of impact in three seasons is peak season $>$ off season $>$ second peak season; the significance of impact of the relative humidity variable in the three seasons is peak season > off season > second peak season; and the precipitation variable is not significant in the three seasons.

Except for the models of the second peak season all samples, weekend samples, and weekends without natural disaster samples, the relative humidity variables are significantly and negatively correlated with the number of tourists; the precipitation is in addition to the peak season sample and the off-season weekend without the natural disaster sample model. Except for the models of peak season weekend samples, off season weekends without natural disaster samples, others are negatively correlated with the number of tourists. Except for the models of second peak season all samples, others are negatively correlated with the number of tourists. The results of the off season regression model of this study are the same as those of Hewer et al. (2016) [13], where the off season model is significantly correlated with the number of tourists, but the temperature is less correlated with the number of tourists, and is significantly related to the weekend because in the cold months, tourists are attracted by natural factors (climate) but more attracted by the system factors (weekend, hunting season).

The whether or not it is a consecutive national holiday coefficients of the off season weekend samples and the season weekends without natural disaster sample models are not significant and are negatively correlated with the number of tourists. After observing the off season weekend in the study data, it was found that the off season model in the study data only has the Dragon Boat Festival consecutive holidays between 6/9/2016 and 6/12/2016, Mid-Autumn Festival between 9/15/2016 and $9 / 18 / 2016$, but in these two consecutive holidays, the number of tourists two weekdays before Dragon 
Boat Festival consecutive holidays without rain reaching the peak, with a total of 1046 persons per day and 1551 persons per day daily during two days, but the two-day weekends were heavy rains, where the total precipitation reached $75 \mathrm{~mm}$ per day and $56 \mathrm{~mm}$ per day, respectively, causing a large decrease in number of tourists, with only a total of 476 persons per day and 534 persons per day in the two-day weekend. The first two weekdays before the Mid-Autumn Festival, the first weekday had light rain of $15 \mathrm{~mm}$ per day, the number of tourists was only 119 persons per day, but the second weekday did not rain, and the number of tourists reached 1391 persons per day, but there was light rain in the following two-day weekend, where the total precipitation reached $15 \mathrm{~mm}$ per day and $14 \mathrm{~mm}$ per day, respectively, resulting in a decrease in the number of tourists to 513 persons per day and 858 persons per day. Therefore, it is estimated that this is the reason why whether or not it is consecutive national holidays coefficient of the off season weekend samples and off season weekends without natural disaster sample models is smaller or even showing a negative correlation when compared with other regression equations.

The precipitation coefficient of the off season without a natural disaster model is larger and shows a positive correlation with the number of tourists when compared with other regression equation coefficients. After observing the study data, it is estimated with two reasons: (1) although the precipitation of the day on 6/26/2016 was $11 \mathrm{~mm}$ per day, the tourist count of the off season weekend was at the highest, reaching 2593 persons per day. However, after assessing other weather data of the day, it was found that the 9:00 relative humidity of the day and the 14:00 relative humidity of the day were only $70 \%$ and $64 \%$, therefore it is inferred that the daytime tourist activity time should be without rain during the day, and it may be raining in the early morning or evening of the day, so although there was $11 \mathrm{~mm}$ per day of precipitation, it was the day with the largest number of tourists in the off season weekend; (2) the 9:00 relative humidity of the day variable coefficient in the off season weekend without a natural disaster model was -10.928 , and the whether or not it is consecutive national holidays variable coefficient was -171.32. The consecutive holidays in the off season weekends without natural disaster model only has Mid-Autumn Festival consecutive holidays between 9/15/2016 and 9/18/2016 in the study data. However, there was rain during this consecutive holidays weekends, where the total precipitation of the day was 15 per day and $14 \mathrm{~mm}$ per day, respectively, and the 9:00 relative humidity of the day was $98 \%$ and $96 \%$, respectively, resulting in a decrease of the tourist count of 513 persons per day and 858 persons per day, respectively. It is estimated that the 9:00 relative humidity coefficient and whether or not it is consecutive national holiday coefficient impacts resulted in the model estimating the tourist count too low; therefore, the total precipitation of the day variable coefficient and the tourist count showed a positive correlation to compensate for the tourist count being too low.

Although the natural disaster coefficient is mostly negative and the coefficient value has significant impact, this only had significance in the peak season weekend samples. It is estimated that the number of tourists in the peak season is high; the impact of a natural disaster on the number of tourists is more significant than that in the second peak season and the off season. The natural disaster variables of peak season all samples are also not significant. It is estimated that it includes the peak season weekday samples, and the number of tourists in the peak season weekday is about $71.23 \%$ of the number of tourists in the peak season weekend, which resulted in the impact of natural disaster being less significant on the weekday samples.

\subsection{Natural Disaster Impact}

This study was based on the prediction of the number of tourists in the future climate change scenario (2020-2100) by the Ministry of Science and Technology (2018) [20]. According to the previous hypothetical scenario of future climate change, a total of six regression equations, including the peak season all samples, second peak season all samples, off season all samples, peak season weekend samples, second peak season weekend samples, and off season weekend samples, were used to calculate the tourist increase of each season and the weekend tourist increase of each season. The results are as follows: Tables 6-12, respectively. Finally, the results of the regression equations of the peak 
season all samples (Table 6), second peak season all samples (Table 7), and off season all samples (Table 8) were added to obtain the total number of tourist increase in one year (Table 9); and the results of the regression equations of peak season weekend samples (Table 10), second peak season weekend samples (Table 11), and off season weekend samples (Table 12) were added to obtain the total number of weekend tourist increase in one year (Table 13).

Table 12. Off season number of weekend tourists increase (persons per season) and increate rate (\%).

\begin{tabular}{lcccccccc}
\hline $\begin{array}{l}\Delta \text { Off Season Weekend Number } \\
\text { of Tourists (Season) }\end{array}$ & \multicolumn{2}{c}{$\begin{array}{c}+\mathbf{1 0} \% \\
\text { Precipitation }\end{array}$} & \multicolumn{2}{c}{$\begin{array}{c}\mathbf{+ 5 \%} \\
\text { Precipitation }\end{array}$} & \multicolumn{2}{c}{$\begin{array}{c}-\mathbf{5 \%} \\
\text { Precipitation }\end{array}$} & \multicolumn{2}{c}{$\begin{array}{c}-\mathbf{1 0 \%} \\
\text { Precipitation }\end{array}$} \\
\hline$+0.5{ }^{\circ} \mathrm{C}$ & 626 & $0.36 \%$ & 633 & $0.36 \%$ & 647 & $0.37 \%$ & 654 & $0.37 \%$ \\
$+1.0^{\circ} \mathrm{C}$ & 1266 & $0.72 \%$ & 1273 & $0.72 \%$ & 1287 & $0.73 \%$ & 1294 & $0.73 \%$ \\
$+1.5{ }^{\circ} \mathrm{C}$ & 1906 & $1.08 \%$ & 1913 & $1.09 \%$ & 1927 & $1.09 \%$ & 1934 & $1.10 \%$ \\
$+2.0^{\circ} \mathrm{C}$ & 2546 & $1.44 \%$ & 2553 & $1.45 \%$ & 2566 & $1.46 \%$ & 2573 & $1.46 \%$ \\
$+2.5{ }^{\circ} \mathrm{C}$ & 3186 & $1.81 \%$ & 3193 & $1.81 \%$ & 3206 & $1.82 \%$ & 3213 & $1.82 \%$ \\
$+3.0^{\circ} \mathrm{C}$ & 3825 & $2.17 \%$ & 3832 & $2.17 \%$ & 3846 & $2.18 \%$ & 3853 & $2.19 \%$ \\
$+3.5^{\circ} \mathrm{C}$ & 4465 & $2.53 \%$ & 4472 & $2.54 \%$ & 4486 & $2.55 \%$ & 4493 & $2.55 \%$ \\
\hline
\end{tabular}

Table 13. Number of weekend tourists increase in one year (persons per season) and increate rate (\%).

\begin{tabular}{|c|c|c|c|c|c|c|c|c|}
\hline \multirow{2}{*}{$\begin{array}{l}\Delta \text { Number of Weekend Tourists } \\
\text { in One Year } \\
+0.5^{\circ} \mathrm{C}\end{array}$} & \multicolumn{2}{|c|}{$\begin{array}{l}+10 \% \\
\text { Precipitation }\end{array}$} & \multicolumn{2}{|c|}{$\begin{array}{l}+5 \% \\
\text { Precipitation }\end{array}$} & \multicolumn{2}{|c|}{$\begin{array}{l}-5 \% \\
\text { Precipitation }\end{array}$} & \multicolumn{2}{|c|}{$\begin{array}{l}-10 \% \\
\text { Precipitation }\end{array}$} \\
\hline & 2622 & $1.49 \%$ & 2728 & $1.55 \%$ & 2940 & $1.67 \%$ & 3045 & $1.73 \%$ \\
\hline$+1.0^{\circ} \mathrm{C}$ & 5456 & $3.10 \%$ & 5562 & $3.16 \%$ & 5773 & $3.28 \%$ & 5879 & $3.34 \%$ \\
\hline$+1.5^{\circ} \mathrm{C}$ & 8289 & $4.70 \%$ & 8395 & $4.76 \%$ & 8607 & $4.88 \%$ & 8713 & $4.94 \%$ \\
\hline$+2.0^{\circ} \mathrm{C}$ & 11,123 & $6.31 \%$ & 11,229 & $6.37 \%$ & 11,441 & $6.49 \%$ & 11,546 & $6.55 \%$ \\
\hline$+2.5^{\circ} \mathrm{C}$ & 13,957 & $7.92 \%$ & 14,063 & $7.98 \%$ & 14,274 & $8.10 \%$ & 14,380 & $8.16 \%$ \\
\hline$+3.0^{\circ} \mathrm{C}$ & 16,790 & $9.53 \%$ & 16,896 & $9.59 \%$ & 17,108 & $9.71 \%$ & 17,214 & $9.77 \%$ \\
\hline$+3.5^{\circ} \mathrm{C}$ & 19,624 & $11.14 \%$ & 19,730 & $11.20 \%$ & 19,942 & $11.32 \%$ & 20,047 & $11.38 \%$ \\
\hline
\end{tabular}

The number of tourists in Huisun Forest Park in 2017 was 176,215 persons. From Table 9, it can be seen that the simulated climate change scenario will lead to an increase of 2737 to 24,457 in the number of tourists in one year, with a growth rate of $1.55 \%$ to $13.88 \%$. From Tables 9 and 13, it can be seen that the increase in weekend tourists in one year accounted for about $81.97 \%$ of the increase of tourists in one year.

From Tables 6-13, it can be seen that in the future simulated climate change scenario, the number of tourists will show an increased condition, because the temperature variable coefficients are much larger than the precipitation variable coefficients regardless of whether or not it is the peak season all samples, second peak season all samples, off season all samples, peak season weekend samples, second peak season weekend samples, or off season weekend samples; in other words, the change of temperature has a much greater impact on the number of tourists than the change of precipitation, which resulted in the increase in the number of tourists.

Different from Hewer et al. (2016) [13] and Jones and Scott (2006a) [5], with rising temperature, the main reason for the increase in tourist count is related to the increase in the number of tourists of the second peak season, while the tourist count in the peak season is only increased slightly. From Tables 6, 9, 10 and 13, this study can observe that regardless of the increase of tourists or the increase of weekend tourists in one year, it is mainly due to the increase of tourists in the peak season, such as the scenario of $+3.5{ }^{\circ} \mathrm{C}$ and $-10 \%$ precipitation, where the increase of tourists in the peak season accounted for approximately $51.44 \%$ of the increase of tourists in one year. It is estimated that because there are three months in the peak season (February, July, August, October), which are school's winter and summer vacations, and February is Lunar New Year most of the time, compared with the second peak season and the off season, more families have free time due to holidays; therefore, when the temperature rises, the willingness to travel increases. The number of people who can go for an outing in the peak season is more than that in the second peak season and off season, which 
eventually resulted in the increase in tourists in one year, mainly due to the increase in tourists in the peak season.

In addition, in order to calculate the change of precipitation when the future temperature is constant, increasing by 0.5 and $1.0^{\circ} \mathrm{C}$, will the number of tourists decrease? This study used the peak season all samples, second peak season all samples, and off season all samples to bring in the temperature and precipitation changes, and added the results of the three models to obtain the change in the number of tourists in one year. The results of this study show that when the temperature is constant, a precipitation increase of $0.02 \%$ will lead to a decrease in the number of tourists; when the temperature rises by $0.5{ }^{\circ} \mathrm{C}$, a precipitation increase of $52 \%$ will result in a decrease in the number of tourists; and when the temperature rises by $1{ }^{\circ} \mathrm{C}$, a precipitation increase of $103 \%$ will result in a decrease in the number of tourists.

Table 14 presents the four scenarios estimated by the Ministry of Science and Technology (2018) [20] and used by this study: annual average temperature and daily average precipitation of 2050 and 2100 at Huisun Forest Park in the scenarios of RCP2.6, optimistic scenario (global warming rate slowed down); RCP4.5 and RCP6.0, second optimistic scenario and second pessimistic scenario (global warming rate remains the same); RCP8.5, pessimistic scenario (global warming increased), after calculating the changes of temperature and precipitation, the change is brought into the regression models of peak season all samples, second peak season all samples, and off season all samples, and the results of the three models were added to obtain the number of tourist increase (persons per year) and increase rate (\%), with a tourist count of 176,215 persons in 2017 as the base year.

Table 14. Number of tourists increase (persons per year) and increase rate (\%) of four scenarios in 2050 and 2100 .

\begin{tabular}{clcc}
\hline \multicolumn{1}{c}{ Scenario } & $\begin{array}{c}\text { Number of Tourists } \\
\text { Increase (Persons per Year) } \\
\text { Compared with 2017 }\end{array}$ & $\begin{array}{c}\text { Change Rate of } \\
\text { Number of Tourists } \\
\text { Compared with 2017 }\end{array}$ \\
\hline \multirow{2}{*}{2050} & 7048 & $4.00 \%$ \\
& Optimistic Scenario (RCP2.6) & 7868 & $4.47 \%$ \\
& Second Optimistic Scenario (RCP4.5) & 6748 & $3.83 \%$ \\
& Second Pessimistic Scenario (RCP6.0) & 10,675 & $6.06 \%$ \\
\cline { 2 - 3 } 2100 & Pessimistic Scenario (RCP8.5) & 5983 & $3.40 \%$ \\
& Optimistic Scenario (RCP2.6) & 10,588 & $6.01 \%$ \\
& Second Optimistic Scenario (RCP4.5) & 14,190 & $8.05 \%$ \\
& Second Pessimistic Scenario (RCP6.0) & 23,813 & $13.51 \%$ \\
\hline
\end{tabular}

\section{Conclusions and Recommendations}

Based on the above discussion, several significant findings are summarized and presented below.

First, the results of this study indicate that the degree of impact that weather has on the number of tourists is the same in the peak season and the off season. The temperature variables and relative humidity variables have a significant impact on the number of tourists, and the precipitation variables are not significant. In the second peak season, only the temperature variables have a significant impact on the number of tourists, and the relative humidity variables and precipitation variables are not significant.

Second, this study found that in all nine models, the temperature variable coefficient values are larger than the relative humidity variable coefficient values and the precipitation variable coefficient values. In other words, the impact of changes in temperature on the number of tourists is higher than the changes of relative humidity and precipitation.

Third, this study supported that the temperature variables are the variables with the most impact in the three seasons, and their impacts are: peak season > off season > second peak season; the impact of the relative humidity variable is: peak season $>$ off season $>$ second peak season; and precipitation variables are not significant in the three seasons. 
Fourth, this study first used one-way ANOVA to analyze the relationship between temperature and number of tourists, and then examined the turning temperature points appearing in each season to obtain the threshold temperature. This study used an ANOVA graph to find the threshold temperature. However, after the ANOVA analysis of the samples of this study, no obvious turning point between temperature and tourists was found; therefore, it is estimated that Huisun Forest Park does not have a threshold temperature. Thus, this study excluded the threshold temperature variables from the regression analysis.

Fifth, the results indicate that under all climate change scenarios (RCP2.6, RCP4.5, RCP6.0, RCP8.5), the tourist counts at Huisun Forest Park show a rising trend, and in the pessimistic scenario of climate change (RCP8.5), which is the worst case of global warming, the number of tourists is actually the highest in all the scenarios, indicating that climate change does not have a negative impact on the number of tourists in the forest park, and may even be positive. Although the tourist count shows an increasing trend under all future climate change scenarios, this study only considered changes in precipitation caused by climate change. If considering natural disasters, such as the frequency of occurrence of typhoons, mudslides, heavy rains, and other natural disasters, there may be a negative impact on the number of tourists to Huisun Forest Park.

Finally, this study identifies that in the context of all climate change scenarios, that is, regardless of whether the scenario of global warming is slowing down or deteriorating, the number of tourists is in an increasing trend. The main reason is that climate change causes an increased temperature, and has a bonus effect on tourism and recreation, and park managers and policy makers need to set new management policies and plans in response to climate change. The tourist counts at Huisun Forest Park in recent years are far from the tourist load, so the growth of the tourist count will not cause a decline in the recreational quality due to an excess number of tourists. Therefore, climate change has positive benefits for Huisun Forest Park. In addition, because the temperature is in a rising trend in all future climate change scenarios, park managers and operators can increase ways to relieve the summer heat to enhance tourists' tourism experience, such as strengthening the maintenance of wading trails and increasing the shade areas of the park and cooling areas (such as gazebos and hammocks or seats under the shade trees), and adding drinking fountains, sinks, shops, cold drink shops, cafes, etc. in the park, and first aid stations in response to heat stroke or heat exhaustion, which can result among tourists from the rising temperatures. As a final note, the results of the regressions presented in this study were only relevant for the current economic and political situation in the world. The worsening of the entire world situation could break the relationships. More factors should be taken into consideration for future studies.

Author Contributions: Three co-authors had together contributed to the completion of this article. W.-Y.L. was the first author drafting the manuscript, and analyzed the data; Y.-H.H. contributed to the investigation, data analysis, the results and conclusion; and C.-M.H. acted as corresponding author on their behalf throughout the review, editing, and submission process. All authors have read and agreed to the published version of the manuscript.

Funding: This research was funded by Taiwan Ministry of Science and Technology. Reference No. MOST 108-2410-H-005-045-MY2, and MOST 107-2410-H-005-043-MY2.

Conflicts of Interest: The authors declare no conflict of interest.

\section{References}

1. Buckley, L.B.; Foushee, M.S. Footprints of climate change in US national park visitation. Int. J. Biometeorol. 2012, 56, 1173-1177. [CrossRef] [PubMed]

2. Fisichelli, N.A.; Schuurman, G.W.; Monahan, W.B. Protected area tourism in a changing climate: Will visitation at US national parks warm up or overheat? PLoS ONE 2015, 10, e0128226. [CrossRef] [PubMed]

3. Hadwen, W.L.; Arthington, A.H.; Boon, P.I.; Taylor, B.; Fellows, C.S. Do climatic or institutional factors drive seasonal patterns of tourism visitation to protected areas across diverse climate zones in eastern Australia? Tour. Geogr. 2011, 13, 187-208. [CrossRef] 
4. Hewer, M.; Scott, M.J.; Gough, W.A. Tourism climatology for camping: A case study of two Ontario parks (Canada). Theor. Appl. Climatol. 2015, 121, 401-411. [CrossRef]

5. Jones, B.; Scott, D. Implications of climate change for visitation to Ontario's provincial parks. Leisure 2006, 30, 233-261. [CrossRef]

6. Jones, B.; Scott, D. Climate change, seasonality and visitation to Canada's national parks. J. Park Recreat. Adm. 2006, 24, 42-62.

7. Loomis, J.; Richardson, R. An external validity test of intended behaviour: Comparing revealed preference and intended visitation in response to climate change. J. Environ. Plann. Man. 2006, 49, 621-630. [CrossRef]

8. Richardson, R.B.; Loomis, J.B. Adaptive recreation planning and climate change: A contingent visitation approach. Ecol. Econ. 2004, 50, 83-99. [CrossRef]

9. Scott, D.; Jones, B.; Konopek, J. Implications of climate and environmental change for nature-based tourism in the Canadian Rocky Mountains: A case study of Waterton Lakes national park. Tour. Manag. 2007, 28, 570-579. [CrossRef]

10. Scott, D.; Gössling, S.; de Freitas, C.R. Preferred climates for tourism: Case studies from Canada, New Zealand and Sweden. Clim. Res. 2008, 38, 61-73. [CrossRef]

11. IPCC (Intergovernmental Panel on Climate Change). Climate Change 2014: Impacts, Adaptation, and Vulnerability. Part A: Global and Sectoral Aspects. Contribution of Working Group II to the Fifth Assessment Report of the Intergovernmental Panel on Climate Change; Field, C.B., Ed.; Cambridge University Press: Cambridge, UK; New York, NY, USA, 2014; p. 190.

12. De Freitas, C.R. Tourism climatology: Evaluating environmental information for decision making and business planning in the recreation and tourism sector. Int. J. Biometeorol. 2003, 48, 45-54. [CrossRef] [PubMed]

13. Hewer, M.; Scott, D.; Fenech, A. Seasonal weather sensitivity, temperature thresholds, and climate change impacts for park visitation. Tour. Geogr. 2016, 18, 297-321. [CrossRef]

14. Smit, B.; Burton, I.; Klein, R.J.T.; Wandel, J. An anatomy of adaptation to climate change and variability. Clim. Chang. 2000, 45, 223-251. [CrossRef]

15. Butler, R.W. Seasonality in tourism: Issues and implications. In Seasonality in Tourism; Baum, T., Lundtorp, S., Eds.; Pergamon: London, UK, 2001; pp. 5-21.

16. Scott, D.; Jones, B.; Konopek, J. Exploring the impact of climate-induced environmental changes on future visitation to Canada's Rocky Mountain national parks. Tour. Rev. Int. 2008, 12, 43-56. [CrossRef]

17. Monahan, W.B.; Fisichelli, N.A. Climate exposure of US national parks in a new era of change. PLoS ONE 2014, 9, 13. [CrossRef] [PubMed]

18. Eagles, P.; Bowman, M.; Tao, T. Guidelines for Tourism in Parks and Protected Areas in East Asia; IUCN: Gland, Switzerland; Cambridge, UK, 2001; p. 114.

19. Eagles, P.; McCool, S.F.; Haynes, C.D. Sustainable Tourism in Protected Areas: Guidelines for Planning and Management; IUCN Publications Services Unit: Cambridge, UK, 2002; p. 183.

20. Taiwan Ministry of Science and Technology. Taiwan Climate Change Projection Information and Adaptation Knowledge Platform (TCCIP) Data Service/Projection. 2018. Available online: https:/tccip.ncdr.nat.gov.tw/ ds_02_eng.aspx (accessed on 3 March 2020).

21. Huisun National Forest Recreation Area. Daily visitation report from November 2015 to June 2018. Available online: https://admin.taiwan.net.tw/FileUploadCategoryListC003330.aspx?CategoryID=2638da16-f46c-429c81f9-3687523da8eb\&appname=FileUploadCategoryListC003330 (accessed on 22 October 2019).

22. Huisun National Forest Recreation Area. Monthly Weather Report from January 2014 to December 2017. Available online: https://www.cwb.gov.tw/V8/C/L/NatForest/NatForest.html?PID=E066 (accessed on 22 October 2019).

23. Tourism Bureau of Ministry of Transportation and Communications. Annual Statistical Report on Tourism 2018. Available online: https://admin.taiwan.net.tw/Handlers/FileHandler.ashx?fid=0ce1616b--6af8--4190-9bd9--c324e6752bc8\&type $=4 \&$ no=1 (accessed on 15 September 2020).

24. IPCC (Intergovernmental Panel on Climate Change). Climate Change 2014: Synthesis Report. Contribution of Working Groups I, II and III to the Fifth Assessment Report of the Intergovernmental Panel on Climate Change; IPCC: Geneva, Switzerland, 2014; p. 151. 
25. Fenech, A.; Comer, N.; Gough, W. Selecting a global climate model for understanding future projections of climate change. In Linking Climate Models to Policy and Decision-Making; Fenech, A., MacLellan, J., Eds.; Environment Canada: Toronto, ON, Canada, 2007; pp. 133-145.

26. Liu, P.L. The Reason Why the Smaller Scale of Downscaling Is Not Better. 2018. Available online: https://tccip.ncdr.nat.gov.tw/km_faq_one.aspx?kid=20150408135422 (accessed on 3 March 2020).

27. Pielke, R.A.; Wilby, R.L. Regional climate downscaling what's the point? Eos Trans. Am. Geophys. Union 2012, 93, 52-53. [CrossRef]

28. Whetton, P.; Hennessy, K.; Clarke, J.; McInnes, K.; Kent, D. Use of representative climate futures in impact and adaptation assessment. Clim. Chang. 2012, 115, 433-442. [CrossRef]

29. De Freitas, C.R. Weather and place-based human behavior: Recreational preferences and sensitivity. Int. J. Biometeorol. 2015, 59, 55-63. [CrossRef] [PubMed]

Publisher's Note: MDPI stays neutral with regard to jurisdictional claims in published maps and institutional affiliations.

(C) 2020 by the authors. Licensee MDPI, Basel, Switzerland. This article is an open access article distributed under the terms and conditions of the Creative Commons Attribution (CC BY) license (http://creativecommons.org/licenses/by/4.0/). 